\title{
Clustering of Observed Diurnal Cycles of Precipitation over the United States for Evaluation of a WRF Multiphysics Regional Climate Ensemble ${ }^{\mathscr{O}}$
}

\author{
P. A. MOONEY \\ National Center for Atmospheric Research, Boulder, Colorado \\ C. BRODERICK \\ Department of Geography, Maynooth University, Kildare, Ireland \\ C. L. BRUYÈRE \\ National Center for Atmospheric Research, Boulder, Colorado \\ F. J. MULLiGAN \\ Department of Experimental Physics, Maynooth University, Kildare, Ireland \\ A. F. PREIN \\ National Center for Atmospheric Research, Boulder, Colorado
}

(Manuscript received 29 November 2016, in final form 11 August 2017)

\begin{abstract}
The diurnal cycle of precipitation during the summer season over the contiguous United States is examined in eight distinct regions. These were identified using cluster analysis applied to the diurnal cycle characteristics at 2141 rainfall gauges over the 10-yr period 1991-2000. Application of the clustering technique provides a physically meaningful way of identifying regions for comparison of model results with observations. The diurnal cycle for each region is specified in terms of 1) total precipitation, 2) frequency of precipitation occurrence, and 3) intensity of precipitation per occurrence on an hourly basis averaged over the 10 -yr period. The amplitude and phase of each element of the diurnal cycle was obtained from harmonic analysis and has been compared with the results of a 24-member multiphysics ensemble of simulations produced by the Weather Research and Forecast (WRF) Model on a region-by-region basis. Three cumulus schemes, two radiation schemes, two microphysics schemes, and two planetary boundary layer schemes were included in the ensemble. Simulations of total precipitation showed reasonable agreement with observations in regions where the diurnal cycle is directly influenced by solar radiation, (e.g., the U.S. Southeast), but they were less successful in regions where other factors influence the diurnal cycle (e.g., the central United States). The diurnal cycle of precipitation frequency and intensity showed substantial biases in the simulations of all eight regions, namely, overestimation of occurrences and underestimation of intensities. Simulations were sensitive to the cumulus and radiation schemes but were largely insensitive to either microphysics or planetary boundary layer schemes.
\end{abstract}

Supplemental information related to this paper is available at the Journals Online website: https://dx.doi.org/10.1175/JCLI-D-160851.s1.

Corresponding author: Dr. P. A. Mooney, pmooney@ucar.edu

\section{Introduction}

The diurnal cycle is one of the most fundamental cycles in Earth's climate system, with many studies (Masson et al. 2012; Oh et al. 2013; Klingaman and Woolnough 2014; Ruppert 2016) suggesting that it influences the 
climate at longer time scales. Of particular importance to the climate system is the diurnal cycle of precipitation, which affects surface hydrology (Dai et al. 1999b), surface radiation, and surface temperature (Dai et al. 1999b); consequently, it has been studied intensively using satellite and surface observations (Wallace 1975; Dai et al. 1999a; Yang and Slingo 2001; Svensson and Jakob 2002; Dai et al. 2007; Twardosz 2007; Kikuchi and Wang 2008; Yaqub et al. 2011; Mooney et al. 2016).

These studies show that in summer, oceanic regions usually have a weak diurnal cycle (mean-to-peak amplitude between $10 \%$ and $30 \%$ of the daily mean amount) and peaks between midnight and early morning. This contrasts with continental regions where observations show that the diurnal cycle of precipitation typically peaks in the late afternoon or early evening and has a mean-to-peak amplitude between $30 \%$ and $100 \%$ of the daily mean precipitation amount.

Other factors also influence the diurnal cycle; for example, there is a strong dependence on the latitude of the location, and such dependence is often stronger than the oceanic-continental one. Additionally, there are local influences on the diurnal cycle such as mountain-valley circulation and land-sea breezes (Oki and Musiake 1994; Dai 2001; Walther et al. 2013; Evans and Westra 2012). One of the most intriguing and commonly studied exceptions to these generalizations is the diurnal cycle of precipitation in the central United States. In this region, the summertime diurnal cycle of precipitation peaks in the early morning, which deviates from the typical late afternoon peak observed in continental regions (Dai et al. 1999a; Carbone et al. 2002; Lee et al. 2008). These studies suggest that the early morning peak arises from long-lived mesoscale convective systems that originate in the Rocky Mountains and propagate eastward in conjunction with the Great Plains low-level jet, which transports moisture from the Gulf of Mexico into the central United States (Bonner 1968).

This behavior in the central United States together with the widespread availability of observational data has led to numerous studies of the diurnal cycle of precipitation over the contiguous United States. Most observational studies have used satellite data (e.g., Prat and Nelson 2014), radar data (e.g., Carbone and Tuttle 2008), gridded data (e.g., Dai et al. 1999a), or some combination thereof (e.g., Sapiano and Arkin 2009). Only a few studies (Wallace 1975; Winkler 1987; Dai 2001; Chen et al. 2009) have utilized gauge data to study the U.S. summertime diurnal cycle of precipitation. All observational studies report an early morning peak in the central United States with afternoon-evening peaks in the east and west of the United States.

Most of these studies on the diurnal cycle of precipitation, regardless of location, have focused exclusively on the total amount of precipitation. Only a few studies (Carbone and Tuttle 2008; Dai et al. 1999a; Dai et al. 2007; Evans and Westra 2012) also considered the diurnal cycle of precipitation frequency and intensity per occurrence. Precipitation frequency shows the number of times it rains in any given period, while intensity per occurrence indicates the average rate of rainfall whenever precipitation occurs (i.e., is rainfall typically light or heavy?). These studies showed that the diurnal cycle of total precipitation amount is largely driven by the diurnal cycle of frequency rather than intensity, which has a much weaker signal.

Representation of the diurnal cycle of precipitation in climate models has received increasing attention in recent years as a model's ability to simulate realistic diurnal cycles is widely considered a good evaluation of the model's physics (Jin et al. 2016). Additionally, recent studies indicate that climate variability is sensitive to diurnal processes, and realistic representations of the diurnal cycle in climate models may improve climate prediction on longer time scales (Ruppert 2016).

Both global climate models (GCMs) and regional climate models (RCMs) that need to parameterize convection struggle to simulate realistic diurnal cycles of precipitation. Most simulated diurnal cycles of total precipitation amount have an amplitude that is too large and a peak that occurs too early over land (e.g., Walther et al. 2013; Dai and Trenberth 2004; Jeong et al. 2011; Diro et al. 2012; Mooney et al. 2016). This is especially true in areas of high heterogeneity or in regions dominated by deep convection (Ban et al. 2014; Argueso et al. 2016; Birch et al. 2015). Another, well-known deficiency of climate models is that they typically overestimate the frequency of occurrence and underestimate the intensity (Dai et al. 1999a, 2007; Mooney et al. 2016). Studies generally attribute these deficiencies to the parameterization of convective processes in the model.

Since cumulus parameterization schemes are generally considered the largest source of uncertainty in simulating the diurnal cycle of precipitation, relatively few regional climate modeling studies have examined the role of other parameterizations and their interactions on the model's performance. Some studies have shown that land surface models can strongly influence the model's ability to represent the diurnal cycle of precipitation (Jin et al. 2010; Pei et al. 2014; Mooney et al. 2016), and convection-permitting studies (e.g., Zhang et al. 2016) have shown that parameterization of turbulence in the planetary boundary layer (Zhang et al. 2016) is important for representing the diurnal cycle. Despite this evidence, the influence of parameterizations other than cumulus schemes continues to be considered negligible. 
Further evidence that other parameterizations could be important is the regional differences that exist in the characteristics of the diurnal cycle. These differences are usually driven by different physical mechanisms (e.g., a low-level jet or sea breeze), which include physical processes other than convection. Therefore, it should be expected that parameterizations other than cumulus could influence the diurnal cycle, particularly in regions where the diurnal cycle is atypical. This study uses an innovative diagnostic approach that clusters observations to examine the role of physical parameterizations in the simulation of the summertime (JJA) diurnal cycle of precipitation across the contiguous United States, an area characterized by strong regional differences.

Clustering was implemented using the $k$-means algorithm (Wilks 2011) to identify regions that possess a similar diurnal cycle of precipitation. This technique has a long history of use for regionalizing climatological data (Perdinan and Winkler 2015). Essentially, this approach groups individual stations according to the characteristics of their diurnal cycle independently of their geographical location. This produces a more natural set of regional divisions for model evaluation compared to the more frequently used approach of selecting latitude-longitude boxes.

The main objective of this study is to evaluate the representation of the diurnal cycle of precipitation in a regional climate model using an innovative diagnostic approach based on the regionalization of observational point scale data. In doing so, we add to current literature by identifying eight different regions across the United States with common summertime diurnal cycle characteristics, highlighting the importance of the interactions between physical parameterizations, and documenting the diurnal cycles of total summer precipitation amount, frequency of occurrences in summer, and intensity per occurrence from over 2000 rain gauges in the contiguous United States over a 10-yr period (1991-2000). The clustering approach used in this study, together with the observational and modeled data, are described in section 2. Results from our analysis of the observed and modeled data are described in section 3, and the paper concludes with a discussion of the findings in section 4 and conclusions in section 5 .

\section{Data and analysis methods}

\section{a. Metrics}

In this study, we define precipitation amount as the total amount of rain that falls during the summer averaged over 10 summers from 1991 to 2000 . This quantity is typically used in studies of the precipitation diurnal cycle; however, it cannot provide any indication of how frequently it rains or whether the rainfall at that location is light or heavy. For this reason, we also consider the diurnal cycle of frequency and intensity, where frequency is the number of occurrences of rainfall per summer averaged over 10 summers. In this case, occurrence is defined as an amount greater than $2.54 \mathrm{~mm}$ in a 1 -h period. Intensity per occurrence represents the average rate of rainfall per occurrence and is obtained by dividing the total amount of rainfall in summer by the number of occurrences. These three metrics are related by the following relationship:

Total amount $=$ No. of occurrences $\times$ intensity.

The normalized amplitude $\tilde{a}$ of a simulation in a particular cluster is the amplitude of that simulation divided by the sum of all simulations in the same cluster. Mathematically, it can be expressed as follows:

$$
\tilde{a}_{c s}=\frac{a_{c s}}{\sum_{s=1}^{24} a_{c s}} .
$$

Here $c$ denotes the cluster number ranging from 1 to 8 and $s$ denotes the simulation number with values from 1 to 24 . The values of the normalized amplitude can range from 0 to 1 . However, in this study, there are 24 simulations so a simulation whose amplitude is the average of all simulated amplitudes in the cluster would have a value of $1 / 24(\sim 0.04)$. In this study, values for the normalized amplitude typically range from 0 to 0.08 , where values close to zero indicate very small amplitudes compared to the average of the cluster and values of 0.08 show that the amplitude is twice the cluster average.

\section{b. Harmonic analysis}

Previous studies of the diurnal cycle (e.g., Wallace 1975; Dai et al. 1999a; Yang and Slingo 2001; Collier and Bowman 2004; Dai et al. 2007; Diro et al. 2012) have used harmonic analysis to quantify diurnal variations in precipitation. The advantages of this approach are that it can estimate the phase and amplitude of the diurnal $(24 \mathrm{~h})$ cycle and quantify the percentage of variance explained by the 24-h cycle. Furthermore, it can be used to quantify variations due to other harmonics, such as the semidiurnal $(12 \mathrm{~h})$ cycle. Hence, this method identifies the diurnal signal and describes its characteristics using a reduced set of easily interpretable parameters.

This study follows the same approach as previous studies to estimate the characteristics of both the diurnal and semidiurnal cycles in the hourly observed and simulated data. The average of each set of 24 hourly samples was subtracted from the set, and the resulting series as a 
function of time $t$ in hours was fit using least squares regression to the following function:

$$
a_{24} \cos \left[2 \pi\left(t-\phi_{24}\right) / 24\right]+a_{12} \cos \left[2 \pi\left(t-\phi_{12}\right) / 12\right],
$$

where $a_{24}\left(a_{12}\right)$ and $\phi_{24}\left(\phi_{12}\right)$ are the amplitude and phase, respectively, of the diurnal (semidiurnal) harmonics. Errors quoted on these parameters throughout this study are the uncertainties estimated from the least squares fit. In this study the phase of the diurnal cycle represents the timing of the maximum in the cycle.

Analysis of the semidiurnal cycle (not shown) revealed that the percentage of variance explained by the 12-h cycle was generally small compared to the 24-h cycle. Therefore, this study focuses exclusively on the diurnal cycle.

\section{c. Observational data}

The DSI-3240 dataset provided by the National Climatic Data Center is used as a reference to evaluate the simulated hourly precipitation (Hammer and Steurer 1997). This observational dataset is unique in terms of its temporal resolution, spatial coverage, and data quality. It is particularly suitable for studying the diurnal cycle of precipitation as it has more realistic amplitudes than gridded data (Dai et al. 1999a). Additionally, it avoids problems encountered by satellites and radar, which are sensitive to cloud cover and light precipitation and to beam blocking by terrain, respectively.

The observations are controlled for losses due to evaporation, errors as a result of the melting of frozen precipitation, and suspiciously high precipitation amounts (Hammer and Steurer 1997). In our analysis, suspicious records were set to missing values. Stations in this dataset use tipping buckets whose measurement sizes are either 0.1 in. $(2.54 \mathrm{~mm})$ or 0.01 in. $(0.254 \mathrm{~mm})$. Precipitation accumulates in the bucket until $2.54 \mathrm{~mm}$ (or $0.254 \mathrm{~mm}$ ) is recorded. This means that light precipitation can accumulate in the bucket for several hours before an occurrence is recorded. While the stations with higher precision instruments are attractive, they are too few to provide sufficient coverage across the contiguous United States. As a result, they were not used in the main analysis of this study, and we selected only stations that observed precipitation in tenths of inches and have data coverage of at least $80 \%$ within the period 1991-2000. These criteria resulted in a total of 2141 stations for the analysis. The amplitude and phase of the diurnal cycle at each station was determined by applying harmonic analysis to the hourly precipitation values as outlined in Mooney et al. (2016). The precision of the instruments also determined the definition of a precipitation occurrence, which in this study is defined as an amount greater than $2.54 \mathrm{~mm}$ in one hour. A study on the effect of the bucket size on the analysis in this study showed that while the bucket size can change the absolute values, as a result of the changing definition of occurrence, the general patterns are independent of the bucket size (see the appendix).

\section{d. Clustering}

To identify regions that possess a similar diurnal cycle of precipitation, individual stations were grouped according to their diurnal phase, amplitude, and mean hourly precipitation. Clustering was implemented using the $k$-means algorithm (Wilks 2011). This technique assigns each station from the multidimensional feature space to one of several clusters according to a distance based similarity criterion. Each cluster is defined by its center point, or centroid, with stations being assigned to the cluster for which the centroid is nearest.

The silhouette index (Rousseeuw 1987) —which considers both the within-cluster cohesion and betweencluster separation-is used to identify the optimum number of clusters. Index values vary between -1 and 1 , with higher values indicating a better clustering solution. The optimal number of clusters is the one that returns the highest average silhouette index.

Here, the silhouette index identified seven clusters as the optimum number. One of these clusters contained two groups of stations that were separated by a large spatial distance-one located in the U.S. Southeast and the other in the eastern Colorado-Kansas region (cluster 8). Although the diurnal cycles of these two groups are very similar, their spatial separation suggests that they are likely due to different physical mechanisms. Therefore, this cluster was divided into two for our analysis. The resulting eight clusters of stations are shown in Fig. 1.

A composite diurnal cycle for each cluster was obtained by averaging the diurnal cycle observed at all the stations in a cluster. The simulated diurnal cycle at the station locations was estimated by inverse distance averaging the four closest grid points around each station. The simulated values for each station location in the cluster were then averaged for comparison with the cluster-averaged observed diurnal cycle. This approach avoids some of the difficulties encountered when comparing precipitation over an individual grid box to a single point, which is also prone to "noise" caused by synoptic and mesoscale variability that can obscure the precipitation peak (Brockhaus et al. 2008).

\section{e. Modeled data}

The multiphysics ensemble used in this study is the U.S. National Center for Atmospheric Research (NCAR) regional climate ensemble developed by Bruyère et al. 


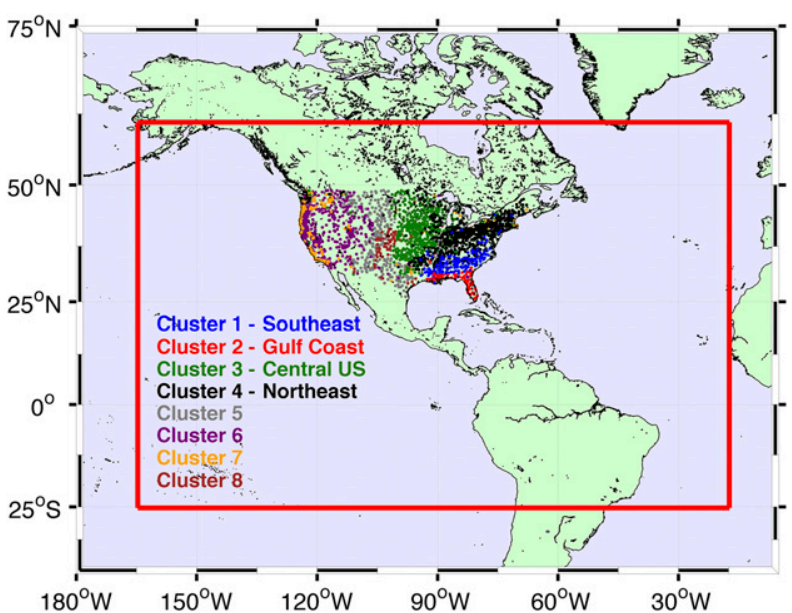

FIG. 1. Map of the WRF domain (red box) showing station locations and their associated clusters.

(2017). It comprises 24 members that differ by combinations of cumulus schemes [Kain-Fritsch (Kain and Fritsch 1990; Kain 2004), new simplified Arakawa-Schubert (NSAS; Han and Pan 2011), or Tiedtke (Tiedtke 1989)], radiation schemes [Community Atmosphere Model (CAM; Collins et al. 2004) or the RRTM for GCMs (RRTMG; Mlawer et al. 1997)], planetary boundary layer (PBL) schemes [Mellor-Yamada-Janjić (MYJ; Mellor and Yamada 1982) or Yonsei University (YSU; Hong et al. 2006)], and microphysics schemes [WSM6 (Hong et al. 2004) or Thompson (Thompson et al. 2008)]. The specific combinations of each ensemble member are summarized in Table 1.

A detailed description of the ensemble is available in Bruyère et al. (2017) and PaiMazumder and Done (2016). For completeness, a brief description of the ensemble is provided here. This regional climate ensemble uses the WRF Model (version 3.5.1; Skamarock et al. 2008) to simulate the climate of North America over the period 1990-2000. In our study, a 1-yr spinup period is employed and only the period 1991-2000 is analyzed. Initial and lateral boundary conditions were provided by ERAInterim (Dee et al. 2011), which previous studies (Mooney et al. 2011; Cornes and Jones 2013; Fu et al. 2015) have shown skillfully reproduces many aspects of the climate system. The domain modeled by WRF is shown in Fig. 1 and the grid spacing is $36 \mathrm{~km}$. All simulations use the Noah land surface model (Ek and Mahrt 1991), which is the most frequently used land surface model in climate modeling studies with the WRF Model (Mooney et al. 2013). Although previous studies (Jin et al. 2010; Gianotti et al. 2012; Pei et al. 2014; Mooney et al. 2016) have shown that the land surface models (LSMs) influence a climate model's ability to simulate the diurnal

TABLE 1. Physical parameterization schemes used in each of the WRF simulations. All 24 simulations use the Noah land surface model. Simulation acronyms are built using CAM $(\mathrm{C})$ or RRTMG $(\mathrm{R})$ radiation schemes; Kain-Fritsch (K), Tiedtke (T), or NSAS (N) convective schemes; WSM6 (6) or Thompson (T) microphysics schemes; and YSU (Y) or MYJ (M) PBL schemes.

\begin{tabular}{|c|c|c|c|c|c|}
\hline No. & Simulation & Radiation & Cumulus & Microphysics & PBL \\
\hline 1 & CK6M & CAM & Kain-Fritsch & WSM6 & MYJ \\
\hline 2 & CK6Y & CAM & Kain-Fritsch & WSM6 & YSU \\
\hline 3 & RK6M & RRTMG & Kain-Fritsch & WSM6 & MYJ \\
\hline 4 & RK6Y & RRTMG & Kain-Fritsch & WSM6 & YSU \\
\hline 5 & CKTM & CAM & Kain-Fritsch & Thompson & MYJ \\
\hline 6 & CKTY & CAM & Kain-Fritsch & Thompson & YSU \\
\hline 7 & RKTM & RRTMG & Kain-Fritsch & Thompson & MYJ \\
\hline 8 & RKTY & RRTMG & Kain-Fritsch & Thompson & YSU \\
\hline 9 & СТ6M & CAM & Tiedtke & WSM6 & MYJ \\
\hline 10 & CT6Y & CAM & Tiedtke & WSM6 & YSU \\
\hline 11 & RT6M & RRTMG & Tiedtke & WSM6 & MYJ \\
\hline 12 & RT6Y & RRTMG & Tiedtke & WSM6 & YSU \\
\hline 13 & СТTM & CAM & Tiedtke & Thompson & MYJ \\
\hline 14 & CTTY & CAM & Tiedtke & Thompson & YSU \\
\hline 15 & RTTM & RRTMG & Tiedtke & Thompson & MYJ \\
\hline 16 & RTTY & RRTMG & Tiedtke & Thompson & YSU \\
\hline 17 & CN6M & CAM & NSAS & WSM6 & MYJ \\
\hline 18 & CN6Y & CAM & NSAS & WSM6 & YSU \\
\hline 19 & RN6M & RRTMG & NSAS & WSM6 & MYJ \\
\hline 20 & RN6Y & RRTMG & NSAS & WSM6 & YSU \\
\hline 21 & CNTM & CAM & NSAS & Thompson & MYJ \\
\hline 22 & CNTY & CAM & NSAS & Thompson & YSU \\
\hline 23 & RNTM & RRTMG & NSAS & Thompson & MYJ \\
\hline 24 & RNTY & RRTMG & NSAS & Thompson & YSU \\
\hline
\end{tabular}


(a)

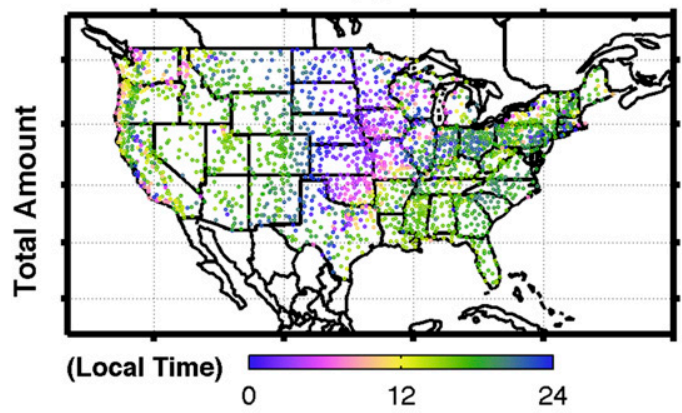

(c)

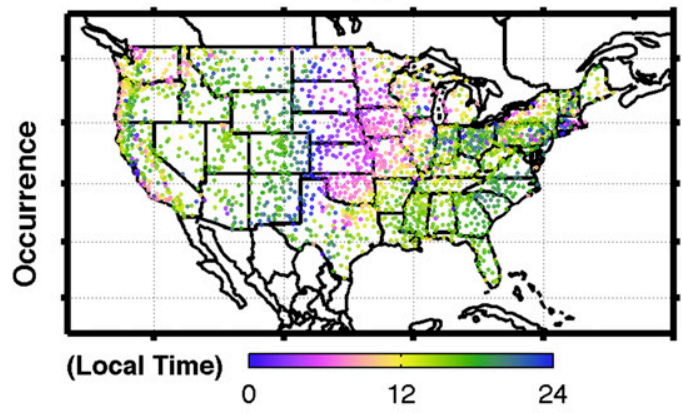

(e)

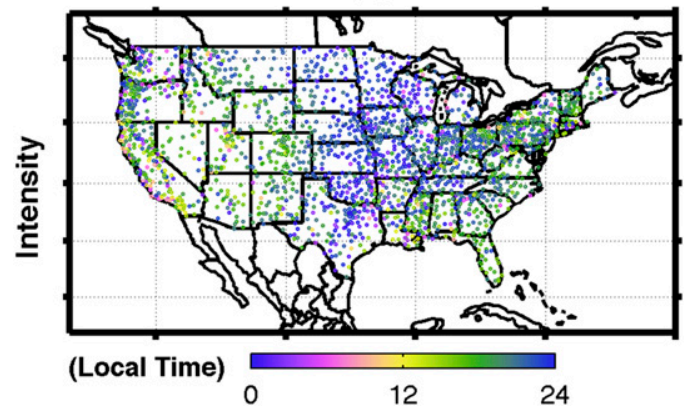

(b)

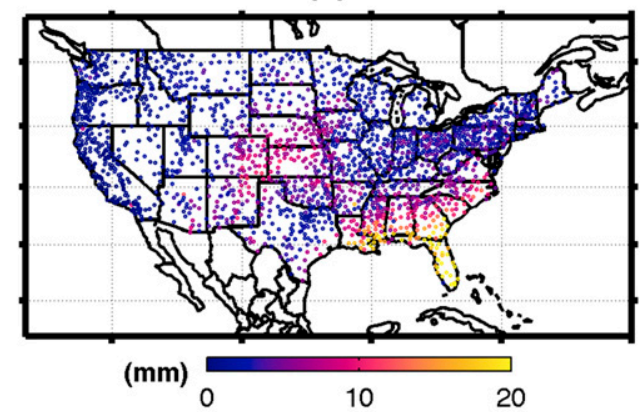

(d)

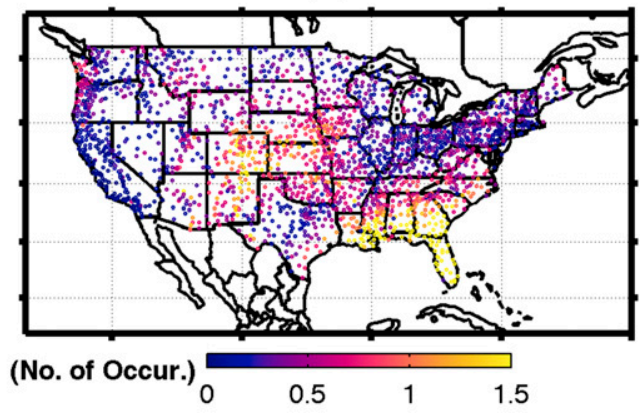

(f)

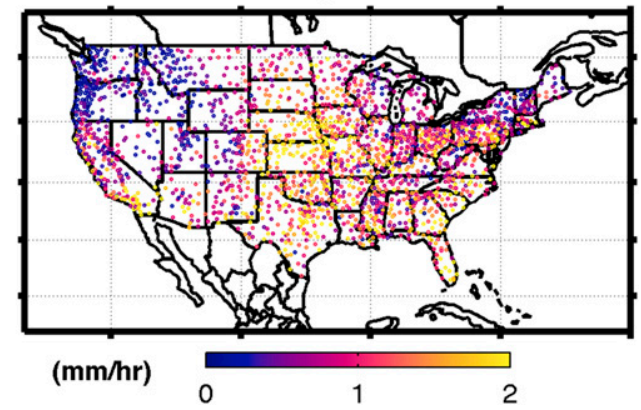

FIG. 2. (a) Phase and (b) amplitude of the 24-h harmonic fitted to the hourly values of total summer (JJA) precipitation amounts recorded at each of the 2141 stations. (c),(d) As in (a),(b), but for total number of precipitation occurrences. (e),(f) As in (a),(b), but for intensity per occurrence.

cycle of precipitation, the availability of just one LSM in this ensemble prevents such an investigation here.

For comparison with the observational data, simulated hourly precipitation at each station is estimated by inverse distance averaging the four closest grid points around each station. The simulated precipitation is discretized into $2.54-\mathrm{mm}$ bins to match the precision of the observational instruments at each location. The harmonic analysis was also performed on the simulated data.

\section{Results}

\section{a. Observed diurnal cycle}

Figure 2 shows the phase (time of maximum amplitude) and amplitude of the 24-h harmonic fitted to the climate mean hourly values of precipitation amount, occurrence, and intensity as observed at each of the 2141 stations throughout the entire summer (JJA) period. The most prominent feature (Fig. 2a) is in the central United States where the phase of the diurnal cycle of amount changes from late afternoon to early morning. This contrasts with the phase of the diurnal cycle in the east and west of the United States, where the phase is similar to other continental regions and occurs between 1500 and 1800 local time (LT). The phase of the diurnal cycle of precipitation amount in the central United States is a well-studied phenomenon, which is generally attributed to the combined effect of long-lived mesoscale convective systems that propagate eastward from the Rockies operating in conjunction with the Great Plains low-level jet, which 
transports moisture northward from the Gulf of Mexico (Carbone and Tuttle 2008).

The amplitude of the observed diurnal cycle of precipitation amount at each individual station is shown in Fig. 2b. Across most of the United States, the observed diurnal cycle of amount has an amplitude less than $5 \mathrm{~mm}$. Three regions are notable exceptions: 1) the eastern Colorado-Kansas region (cluster 8), which has an amplitude between 5 and $10 \mathrm{~mm}$; 2) the Gulf Coast region, which has the highest amplitudes between 20 and $25 \mathrm{~mm}$; and 3) the U.S. Southeast region, which has amplitudes between 10 and $15 \mathrm{~mm}$.

Figures $2 \mathrm{c}$ and $2 \mathrm{~d}$ show the phase and amplitude of the observed diurnal cycle of occurrence, respectively, which is defined as 0.1 in. $(2.54 \mathrm{~mm})$. Figures $2 \mathrm{c}$, d have very similar spatial patterns to the corresponding Figs. 2a,b for the observed diurnal cycle of precipitation amount. This agrees with Dai et al. (2007), who show that the diurnal cycle of precipitation is driven primarily by occurrences rather than by intensity. The phase of the diurnal cycle of occurrence generally occurs in the late afternoon in the east and west of the United States and gradually changes from late afternoon to early morning in the central United States. The amplitude of the diurnal cycle of occurrence is less than 0.5 occurrences per hour during the summer in most of the United States with the three regions mentioned in the previous paragraph exhibiting above-average values that are between 1.0 and 2.0 occurrences.

Figures $2 \mathrm{e}$ and $2 \mathrm{f}$ show the phase and amplitude of the diurnal cycle of intensity per occurrence, respectively. The phase shows very little spatial variation with most stations showing a late evening phase. The amplitude of the diurnal cycle of intensity shows a higher amplitude in the central United States, the Southeast, and the Gulf Coast than in the U.S. West Coast, the Rockies, and the U.S. Northeast.

\section{COMPARING GRIDDED MODELED DATA WITH OBSERVED STATION DATA}

Local variations that can influence the hourly values at individual stations are generally not well represented in climate models with $36-\mathrm{km}$ grid spacing. This presents difficulties when comparing the observed diurnal cycle at a single station with the simulated diurnal cycle. One possible approach to overcome some of this difficulty is to perform comparisons on cluster averages instead of individual stations.

To demonstrate the validity of this approach, the explained variance of individual stations in a cluster and the mean of all stations in the cluster are shown in Fig. 3a along with the observed hourly values of total rainfall amount during summer (JJA) for all 143 stations in the
Southeast cluster. Each station in this cluster is plotted as a gray line, and the thick black line indicates the average of all stations with the plus or minus one standard deviation $( \pm 1 \sigma)$ values shown in blue. The purple line in the plot shows the 24-h harmonic fitted to the average hourly values. This $24-h$ harmonic accounts for $87 \%$ of the variation in the hourly values averaged over all stations in the Southeast cluster. This contrasts with the variance explained by the 24 -h harmonic fitted to each individual station, which is shown on the map in Fig. 3b. At individual stations, the 24-h harmonic accounts for $50 \%-60 \%$ of the variation. This is much less than the variance explained by the 24-h harmonic fitted to the hourly values averaged over all stations. While this result is also evident in the other clusters, it is most pronounced in the Northeast cluster (Figs. 3c,d). Here, the 24-h harmonic is responsible for $78 \%$ of the variance of the hourly values averaged over all stations in the cluster (Fig. 3c), whereas the 24-h harmonic explains less than $40 \%$ of the variation at individual stations (Fig. 3d).

The lower explained variance at the level of individual stations is partially due to the influence of synoptic scale and mesoscale variability, which add noise to the diurnal signal (Brockhaus et al. 2008). However, averaging the hourly values from all stations in a cluster removes some of this noise and leads to a higher explained variance. Therefore, comparisons between observations and simulations are performed on cluster averages throughout the remainder of this manuscript.

\section{b. Simulated diurnal cycle}

Figure 4 shows the phase and amplitude of the observed (black squares) and simulated (colored symbols) diurnal cycle of total summer precipitation amount, occurrences per summer (JJA), and intensity per occurrence averaged over each of the eight clusters (Fig. 1). In six of the eight clusters, the observations (black squares) of the diurnal cycle of total summer precipitation amount, occurrences per summer and the intensity per occurrence have a phase between 1500 and 2000 LT. Clusters 3 and 7 have considerably different phases. Cluster 7, which consists mainly of coastal stations, has an observed morning phase of $0848 \mathrm{LT} \pm$ $19 \mathrm{~min}$ for the diurnal cycle of amount and $0914 \mathrm{LT} \pm$ $11 \mathrm{~min}$ for the diurnal cycle of occurrences. In cluster 3 , the observed diurnal cycle of total precipitation amount has a phase of $0339 \mathrm{LT} \pm 1 \mathrm{~min}$ while the diurnal cycle of occurrences has a phase of $0618 \mathrm{LT} \pm 8 \mathrm{~min}$. This deviation from the other clusters presents a significant challenge for regional climate models and is evident in the large spread of simulated values that differ from the observations. 
(a)

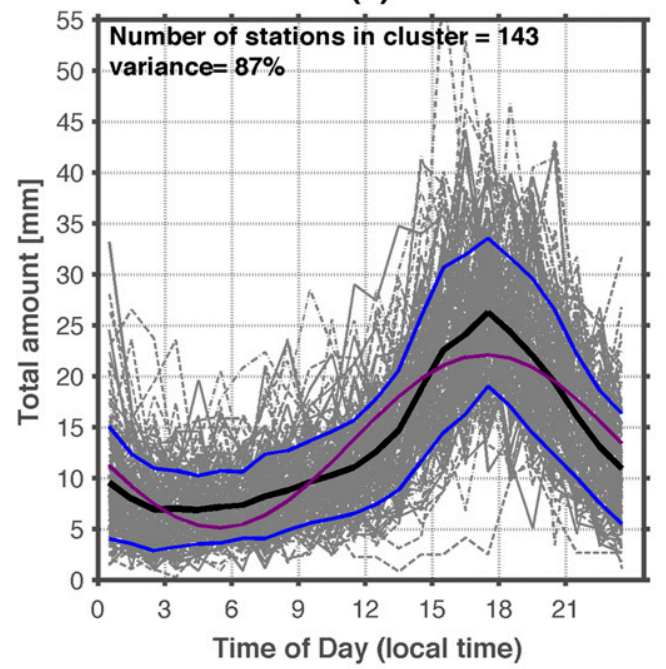

(b)

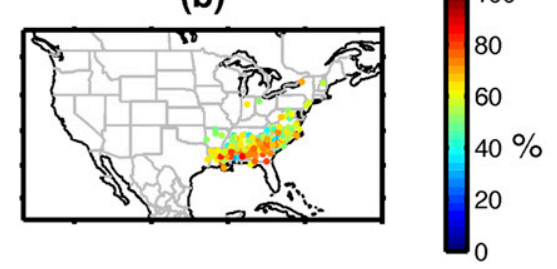

(c)

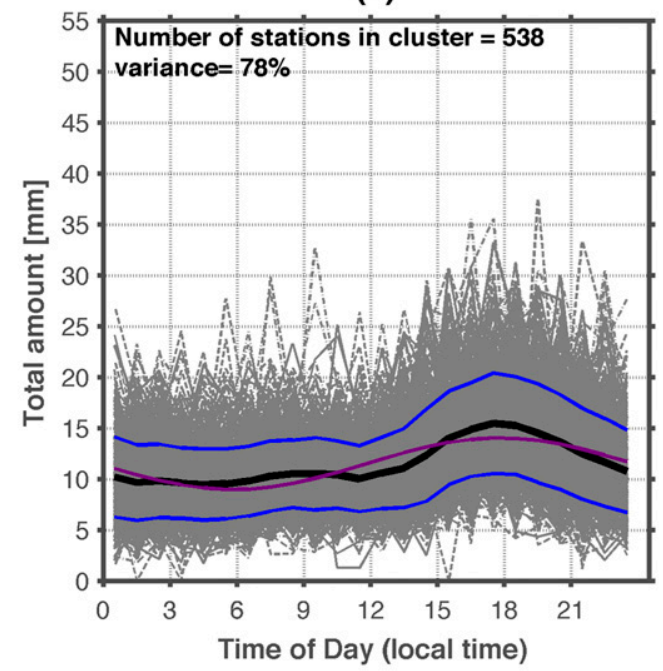

(d)

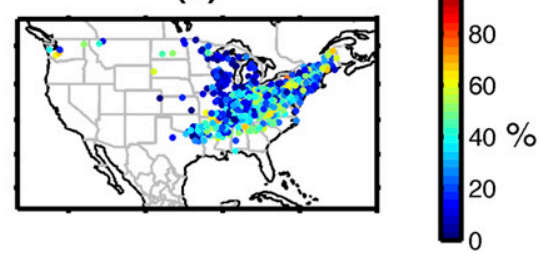

FIG. 3. (a) Total summer rainfall amount at each station in the Southeast cluster for every hour of the day (gray lines). Also shown is the total summer rainfall amount averaged over all stations in the cluster (thick black line), the standard deviation (thick blue lines), and the corresponding 24-h harmonic (thick purple line). (b) Variance explained by the 24-h harmonic fitted to the diurnal cycle of total summer rainfall observed at each station in the Southeast cluster. (c),(d) As in (a),(b), but for the Northeast cluster.

The spread in the simulated phase is largest in this cluster and the simulated phases are clearly influenced by the cumulus schemes. In general, both the KainFritsch and Tiedtke schemes simulate phases that are closer to the afternoon (i.e., time of maximum incoming solar radiation). This reflects the strong influence of surface forcing on these schemes, even in regions such as the central United States where the diurnal cycle of precipitation is not dominated by surface forcing. This contrasts with NSAS, which has a nighttime phase, and reflects the coupling of this scheme to large-scale processes, such as the Great Plains low-level jet. However, NSAS simulations are unable to capture other processes responsible for the diurnal cycle in this region such as the eastward-propagating convective systems that originate in the Rockies. Consequently, it simulates phases that occur a few hours earlier than observed.

The observed amplitude of the diurnal cycle of total summer precipitation amount is less than $9.5 \mathrm{~mm}$ in seven of the eight clusters. Cluster 2 is noteworthy, having a relatively large amplitude of $18.7 \pm 0.48 \mathrm{~mm}$. Similarly, the diurnal cycle of occurrences in this cluster has an above-average amplitude of $2.00 \pm 0.04$ occurrences compared to the other clusters whose amplitudes range between 0.2 and 1.0 occurrences (Fig. 4e). In general, WRF can simulate the amplitude of the diurnal cycle of total amount; however, it overestimates the amplitude of occurrences and underestimates the intensity per occurrence. There are some exceptions to this generalization. WRF struggles to simulate the amplitude of amount and occurrence in clusters 1 and 2, which show a clear contrast between the simulations using alternate cumulus schemes. Figure 4 also shows distinct differences between simulations using different radiation schemes [CAM (circles) and RRTMG (triangles)]. Additionally, Fig. 4 shows some indication that the planetary boundary layer and microphysics schemes may influence the simulated diurnal cycle, but only when they are combined with certain radiation and cumulus schemes.

\section{c. Influence of cumulus parameterizations}

Evaluation of the physical parameterizations in the WRF ensemble focuses only on the first three clusters shown in Fig. 1, referred to as 1) U.S. Southeast, 2) Gulf 
(a) Amount

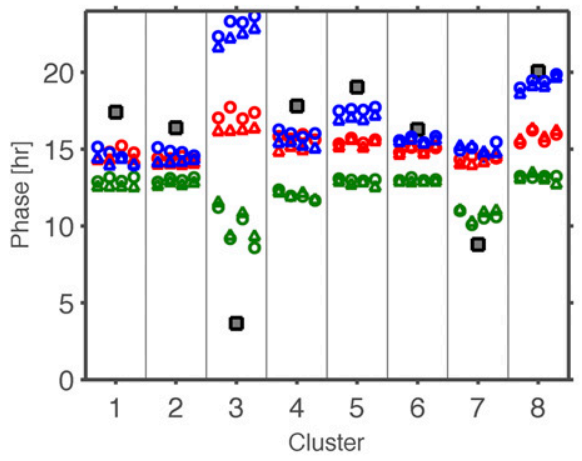

(b) No. of occurrence

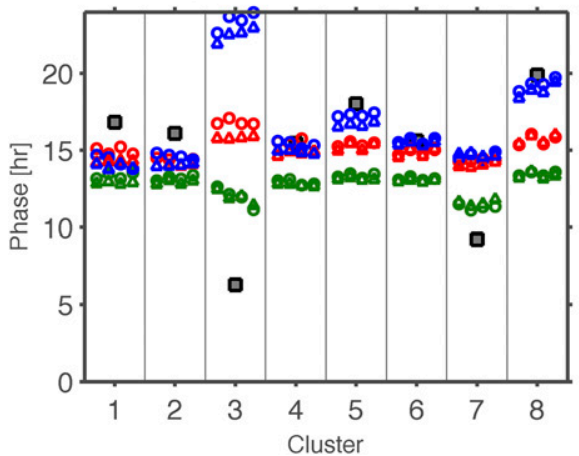

(c) Intensity per occurrence

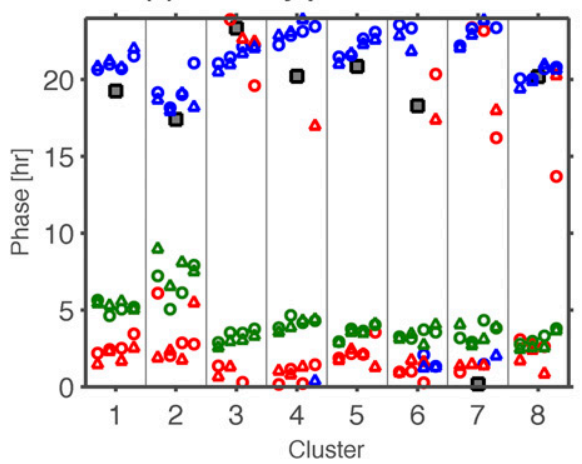

(d) Amount

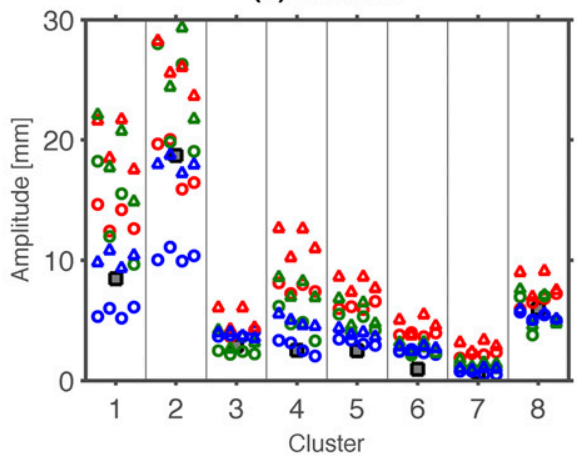

(e) No. of occurrence

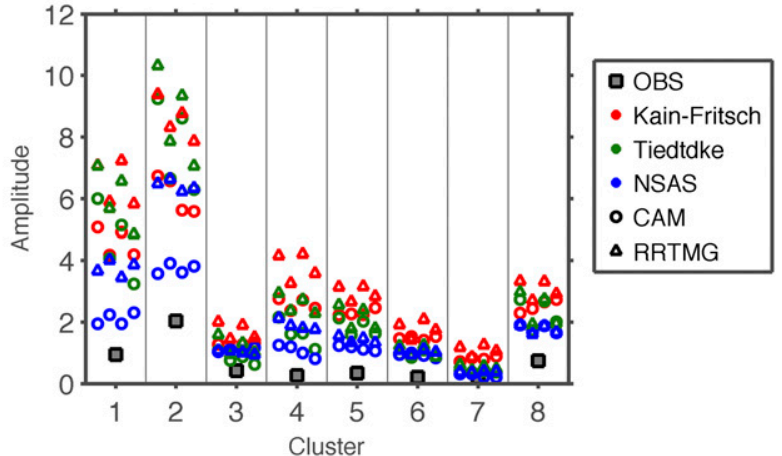

(f) Intensity per occurrence

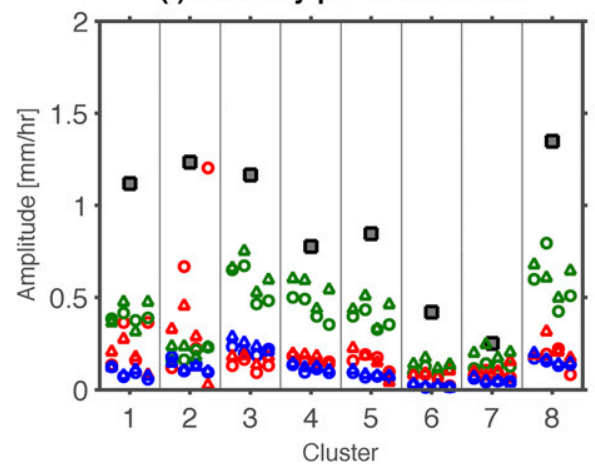

FIG. 4. Phase of the diurnal cycle of (a) precipitation amount, (b) number of occurrences, and (c) intensity per occurrence. Amplitude of the diurnal cycle of (d) precipitation amount, (e) number of occurrences, and (f) intensity per occurrence. Simulations colored red use the Kain-Fritsch cumulus scheme, blue use NSAS, and green use Tiedtke. Simulations using the CAM radiation scheme are identified by open circles and those with RRTMG by triangles. In each cluster, all the simulations in the first column use the WSM6 microphysics and the MYJ PBL schemes, the second column use WSM6 and YSU, the third column use Thompson and MYJ, and the fourth column use Thompson and YSU. Observations are shown as black squares.

Coast, and 3) central United States throughout the rest of this manuscript. The Southeast cluster is examined because it exhibits the typical traits of a summertime continental diurnal cycle and has a well-defined cycle. The Gulf Coast and central U.S. clusters were chosen because their unusual characteristics present unique challenges for RCMs.

Figure 5 shows the diurnal cycle of total summer precipitation amount, occurrences, and intensity per occurrence for three different clusters (corresponding plots for the other five clusters are shown in the supplementary material). The 24 simulations are divided into three subensembles - each with eight simulations conducted using a common cumulus scheme, either Kain-Fritsch, Tiedtke, or NSAS. For clarity, Fig. 5 shows only the mean (solid line) and the standard deviation (shaded region) of each eight-member ensemble. 
(a)

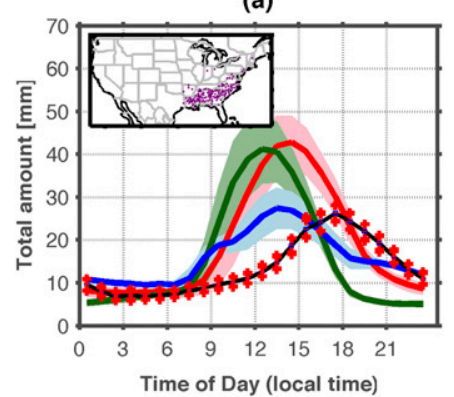

(d)

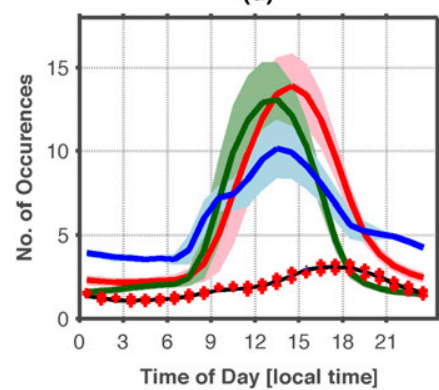

(g)

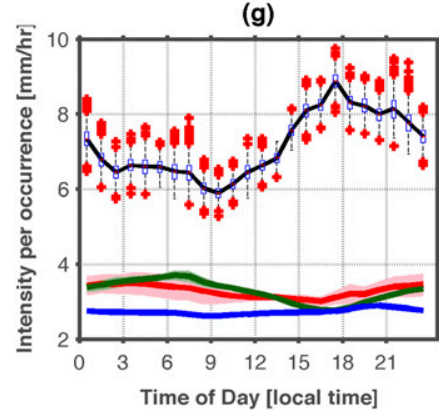

(b)

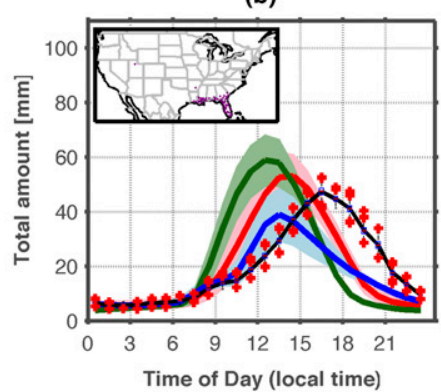

(e)

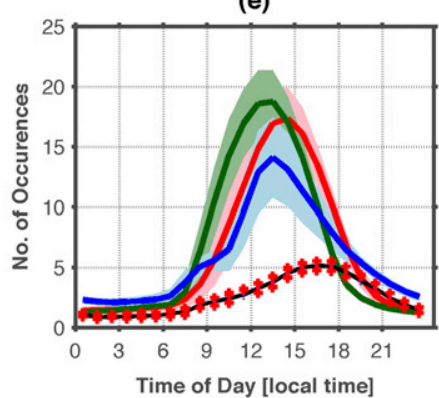

(h)

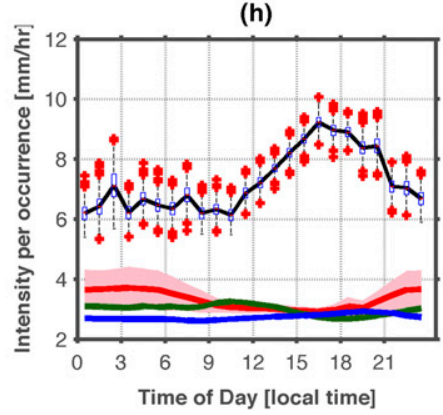

(c)

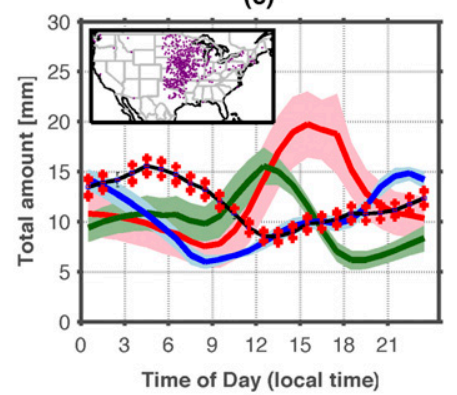

(f)

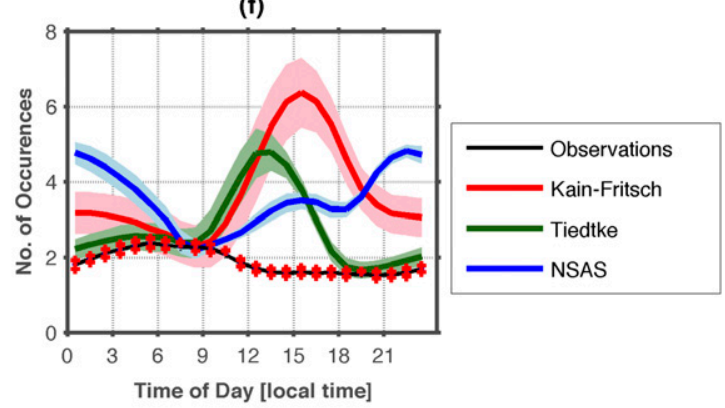

(i)

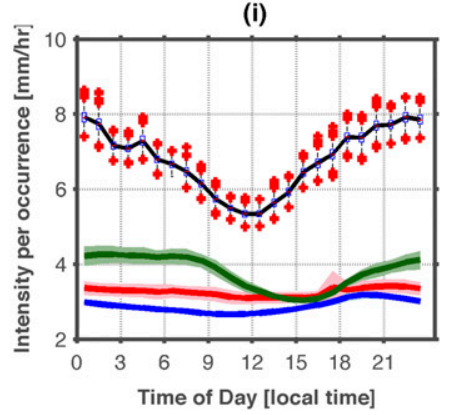

FIG. 5. Mean diurnal cycle of (a)-(c) precipitation amount, (d)-(f) occurrences, and (g)-(i) intensity for three clusters. The clusters shown are (left) Southeast, (center) Gulf Coast, and (right) central United States. The box plots represent the observations, while the ensemble mean of simulations using the Tiedtke, Kain-Fritsch, and NSAS cumulus schemes are shown in red, green, and blue, respectively. The simulation mean is shown as solid lines, while the shading indicates the standard deviation for each of the eight ensemble members.

\section{1) Total RAINFALL AMOUNT}

The observed diurnal cycle of precipitation amount (black line in Fig. 5a) over the Southeast (cluster 1) has a phase of $1735 \mathrm{LT} \pm 5 \mathrm{~min}$. All of the cumulus ensembles simulate a peak that occurs too early. This behavior is also observed in all clusters except the central United States (Fig. 5c) where the timing of the peak is driven by different physical processes, namely, the eastward propagation of MCSs and the low-level jet. No simulation accurately reproduces the anomalous nighttime phase $0329 \mathrm{LT} \pm 1 \mathrm{~min}$ over the central U.S. cluster. However, unlike the other schemes, the NSAS ensemble mean does simulate a nighttime phase (2244 LT $\pm 14 \mathrm{~min}$ ).

In the Southeast cluster, Table 2 shows that the observed diurnal cycle of precipitation amount has an amplitude of $8.5 \pm 0.25 \mathrm{~mm}$. The NSAS ensemble mean has an amplitude $(7.8 \pm 0.29 \mathrm{~mm})$ that is very close to the observations compared to the amplitudes of both the Kain-Fritsch and Tiedtke ensemble means $(16.5 \pm 0.31$ and $16.3 \pm 0.56 \mathrm{~mm}$, respectively). This result is found in all clusters that have typical diurnal cycles; exceptions are the Gulf Coast (cluster 2) and central U.S. cluster (cluster 3), which have atypical cycles.

Table 2 shows that the observed cycle over the Gulf Coast has an average amplitude of $18.7 \pm 0.48 \mathrm{~mm}$. The NSAS ensemble mean has the lowest amplitude (14.1 \pm $0.67 \mathrm{~mm}$ ), which is also lower than the observed amplitude. Both the Kain-Fritsch and Tiedtke ensemble means overestimate the amplitude with values of $21.8 \pm$ 0.48 and $25.1 \pm 0.77 \mathrm{~mm}$, respectively. This pattern 
TABLE 2. Amplitudes of the 24-h harmonic fitted to the simulated and observed hourly values for all 8 clusters are shown at the top of the table. The first row is observations; rows 2, 3, and 4 represent 8 members of the 24-member ensemble that have a common cumulus parameterization that is used to label the 8 -member subensemble; and rows 5 and 6 represent 12 members of the 24 -member ensemble that have a common radiation scheme that is used to label the 12 -member subensemble. The values in parentheses are the $-1 \sigma$ uncertainties on the quoted values estimated from the least squares fit. The middle of the table, as in the top, but for the number of occurrences during June, July, and August. The bottom of the table, as in the top, but for the intensity of precipitation during June, July, and August.

\begin{tabular}{|c|c|c|c|c|c|c|c|c|}
\hline & \multicolumn{8}{|c|}{ Clusters } \\
\hline & 1 & 2 & 3 & 4 & 5 & 6 & 7 & 8 \\
\hline \multicolumn{9}{|c|}{ Total summer rainfall $(\mathrm{mm})$} \\
\hline Observations & $8.5(0.25)$ & $18.7(0.48)$ & $2.9(0.09)$ & $2.5(0.12)$ & $2.5(0.12)$ & $0.9(0.03)$ & $0.7(0.04)$ & $6.0(0.20)$ \\
\hline Kain-Fritsch ensemble & $16.5(0.31)$ & $21.8(0.48)$ & $4.4(0.19)$ & $9.6(0.24)$ & $7.1(0.19)$ & $4.2(0.11)$ & $2.5(0.07)$ & $7.3(0.23)$ \\
\hline Tiedtke ensemble & $16.3(0.56)$ & $25.1(0.77)$ & $2.8(0.2)$ & $6.2(0.29)$ & $5.2(0.22)$ & $2.6(0.11)$ & $1.3(0.08)$ & $5.8(0.26)$ \\
\hline NSAS ensemble & $7.8(0.29)$ & $14.1(0.67)$ & $3.7(0.16)$ & $3.8(0.12)$ & $3.5(0.19)$ & $2.5(0.08)$ & $0.8(0.06)$ & $5.3(0.39)$ \\
\hline CAM ensemble & $10.6(0.37)$ & $16.8(0.53)$ & $1.2(0.16)$ & $4.5(0.22)$ & $4.2(0.19)$ & $2.7(0.10)$ & $1.1(0.07)$ & $4.7(0.27)$ \\
\hline RRTMG ensemble & $15.9(0.28)$ & $23.3(0.46)$ & $1.8(0.16)$ & $7.5(0.15)$ & $5.4(0.14)$ & $3.2(0.08)$ & $1.6(0.06)$ & $5.3(0.22)$ \\
\hline \multicolumn{9}{|c|}{ Frequency of occurrence } \\
\hline Observations & $0.9(0.02)$ & $2.0(0.04)$ & $0.4(0.01)$ & $0.3(0.02)$ & $0.4(0.02)$ & $0.2(0.01)$ & $0.2(0.01)$ & $0.7(0.03)$ \\
\hline Kain-Fritsch ensemble & $5.5(0.10)$ & $7.3(0.16)$ & $1.5(0.06)$ & $3.2(0.08)$ & $2.6(0.07)$ & $1.6(0.04)$ & $0.9(0.02)$ & $2.8(0.09)$ \\
\hline Tiedtke ensemble & $5.3(0.16)$ & $8.2(0.20)$ & $1.0(0.08)$ & $2.1(0.09)$ & $2.0(0.08)$ & $1.0(0.04)$ & $0.5(0.03)$ & $2.3(0.10)$ \\
\hline NSAS ensemble & $2.9(0.11)$ & $5.0(0.24)$ & $1.0(0.05)$ & $1.5(0.05)$ & $1.3(0.07)$ & $1.0(0.03)$ & $0.3(0.02)$ & $1.7(0.14)$ \\
\hline CAM ensemble & $3.7(0.12)$ & $5.7(0.17)$ & $0.4(0.06)$ & $1.7(0.07)$ & $1.6(0.07)$ & $1.1(0.04)$ & $0.5(0.02)$ & $1.8(0.10)$ \\
\hline RRTMG ensemble & $5.4(0.08)$ & $7.8(0.14)$ & $0.7(0.05)$ & $2.7(0.05)$ & $2.0(0.05)$ & $1.3(0.03)$ & $0.6(0.02)$ & $2.1(0.09)$ \\
\hline \multicolumn{9}{|c|}{ Intensity per occurrence $\left(\mathrm{mm} \mathrm{h}^{-1}\right)$} \\
\hline Observations & $0.8(0.04)$ & $1.2(0.08)$ & $1.1(0.05)$ & $0.7(0.03)$ & $0.9(0.04)$ & $0.4(0.02)$ & $0.2(0.06)$ & $1.4(0.05)$ \\
\hline Kain-Fritsch ensemble & $0.1(0.01)$ & $0.4(0.02)$ & $0.1(0.01)$ & $0.1(0.01)$ & $0.2(0.01)$ & $0.1(0.01)$ & $0.1(0.01)$ & $0.2(0.01)$ \\
\hline Tiedtke ensemble & $0.5(0.01)$ & $0.2(0.01)$ & $0.6(0.01)$ & $0.3(0.01)$ & $0.4(0.01)$ & $0.1(0.01)$ & $0.2(0.01)$ & $0.6(0.02)$ \\
\hline NSAS ensemble & $0.1(0.01)$ & $0.1(0.01)$ & $0.2(0.01)$ & $0.1(0.01)$ & $0.1(0.01)$ & $0.1(0.01)$ & $0.1(0.01)$ & $0.2(0.01)$ \\
\hline CAM ensemble & $0.2(0.01)$ & $0.2(0.01)$ & $0.2(0.01)$ & $0.1(0.01)$ & $0.2(0.01)$ & $0.1(0.01)$ & $0.1(0.01)$ & $0.2(0.01)$ \\
\hline RRTMG ensemble & $0.2(0.01)$ & $0.1(0.01)$ & $0.3(0.01)$ & $0.1(0.01)$ & $0.2(0.01)$ & $0.1(0.01)$ & $0.1(0.01)$ & $0.3(0.01)$ \\
\hline
\end{tabular}

is reflected in Fig. 5b, which also shows that all three ensembles simulate a peak that is too early compared to the observations, which has a phase of $1624 \mathrm{LT}$ $\pm 2 \mathrm{~min}$. This is consistent with previous studies over other subtropical regions with both global and regional climate models.

\section{2) FREQUENCY OF OCCURRENCE}

All cumulus ensemble means overestimate the occurrences at all hours in every cluster, and the hourly values have a peak that is too large compared to the observations. This is evident in Figs. 5d-f, which shows the simulated and observed hourly values in both typical and atypical clusters. In all clusters, the NSAS ensemble mean has the lowest peak and is closer to the observations than the other ensembles.

In most clusters, all cumulus ensemble means peak too early compared to the observations. The only exception to this is the central U.S. cluster where the observed peak occurs in the early morning instead of the late afternoon peak - as is the case for the other clusters. Figure $5 \mathrm{f}$ shows that in the central U.S. cluster, only the NSAS ensemble mean peaks late at night. This contrasts with the Tiedtke and Kain-Fritsch ensembles, which peak in the afternoon. This suggests that simulations with these two schemes fail to capture the physical processes that underlie the diurnal cycle in this region while the NSAS simulations can capture some of the physical processes.

\section{3) INTENSITY PER OCCURRENCE}

Figures $5 \mathrm{~g}$ and $5 \mathrm{~h}$ show that the observed hourly values of intensity per occurrence peak in the late afternoon in both the Southeast and Gulf Coast clusters, respectively. In these clusters, the NSAS ensemble means peak late in the evening, which is closer to the time of the observed peaks than either Kain-Fritsch or Tiedtke. This behavior is evident in all clusters except the central U.S. cluster where the observed hourly values peak in the early morning as shown in Fig. 5 i. Here, the Tiedtke ensemble mean peaks early in the morning, which is closer to the observed time than the other two ensembles.

In all clusters, the simulated hourly values are substantially lower than the observed values and show less variability throughout the day. Table 2 shows that all ensemble means have amplitudes that are too low compared to the observed amplitudes. In general, all cumulus ensembles underestimate the intensity in all clusters. 
(a)

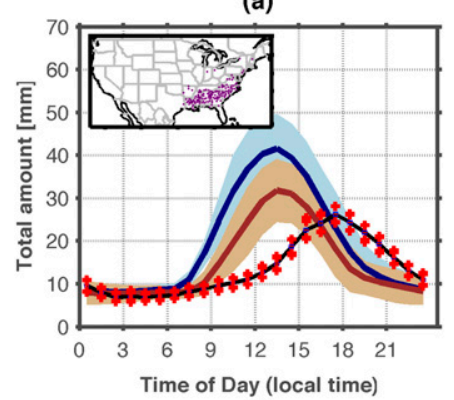

(d)

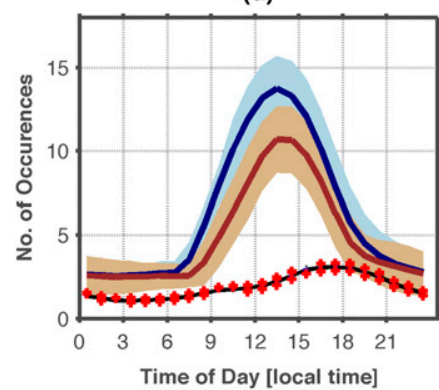

(g)

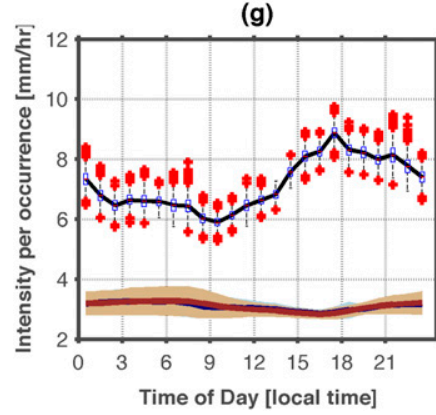

(b)

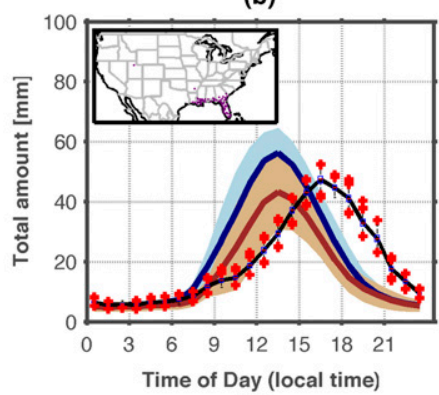

(e)

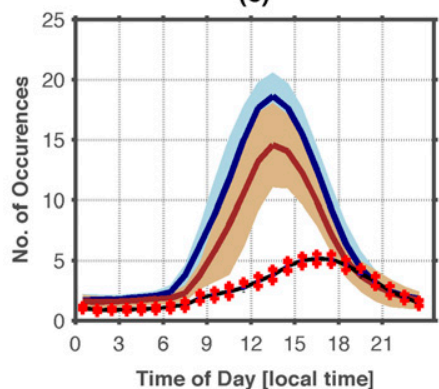

(h)

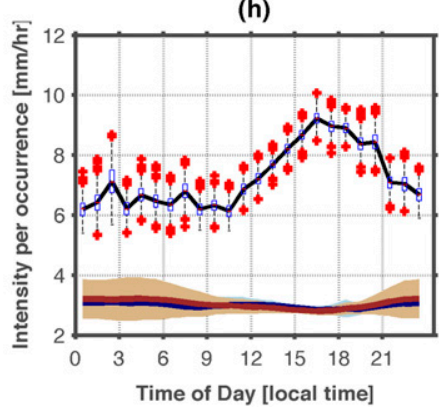

(c)

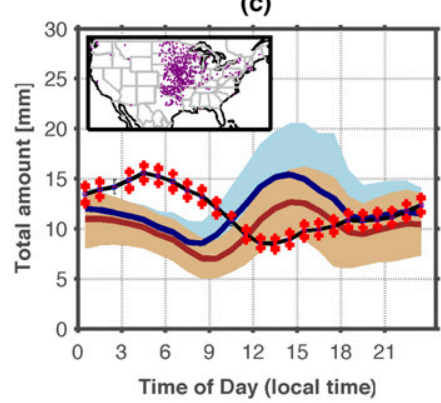

(f)

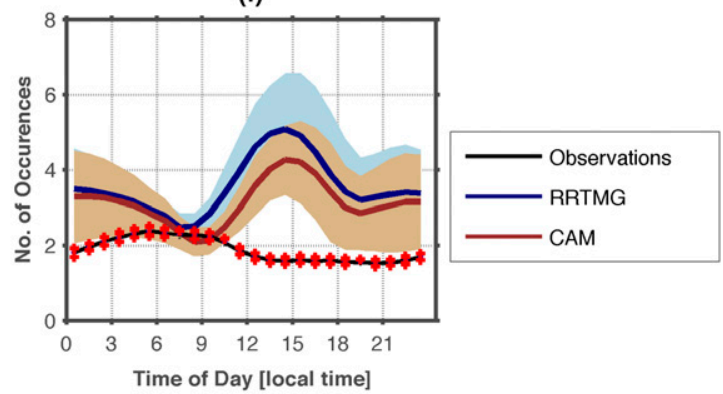

(i)

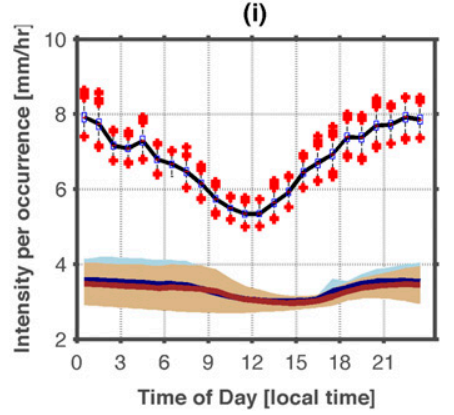

FIG. 6. Mean diurnal cycle of (a)-(c) precipitation amount, (d)-(f) occurrences, and (g)-(i) intensity for three clusters. The clusters shown are (left) Southeast, (center) Gulf Coast, and (right) central United States. The box plots represent the observations, while the ensemble mean of simulations using the RRTMG and CAM radiation schemes are shown in blue and red, respectively. The simulation mean is shown as solid lines, while the shading indicates the standard deviation for each of the 12 ensemble members.

\section{d. Influence of radiation schemes}

Figure 4 indicates that radiation schemes can have a discernible influence on the simulated cycle, but its influence is not as important as the cumulus schemes. To get a clearer picture of the effect of the radiation scheme, the 24-member ensemble was divided into two 12member subensembles based on the radiation scheme, either CAM or RRTMG. Figure 6 shows the diurnal cycle of total summer precipitation amount, occurrences, and intensity per occurrence for each of the three clusters (Southeast, Gulf Coast, and central United States). Similar plots for the other five clusters are shown in the supplementary material. In general simulations with the CAM radiation scheme produce a lower amount and fewer occurrences of precipitation than simulations with RRTMG. This is particularly noticeable in the Southeast and Gulf Coast clusters. Radiation schemes have very little impact on WRF's ability to simulate the phase of the diurnal cycles of total summer precipitation amount and occurrences in the Southeast and Gulf Coast clusters; this is also evident in Fig. 4, which shows that only the simulated phase in the central United States (cluster 3) is affected by the radiation schemes. Table 2 shows that the radiation schemes did impact the amplitude of the 24-h harmonic fitted to the hourly values of the ensemble means, with CAM simulations generally having a lower amplitude than those from RRTMG. Figures $6 \mathrm{~g}$ and $6 \mathrm{~h}$ show that the diurnal cycles of total summer amount and occurrences, respectively, in the central United States peak slightly later in the CAM ensemble than in the RRTMG ensemble. In general, the radiation schemes influence the model's ability to simulate the diurnal cycle of precipitation, albeit to a lesser extent than the cumulus 

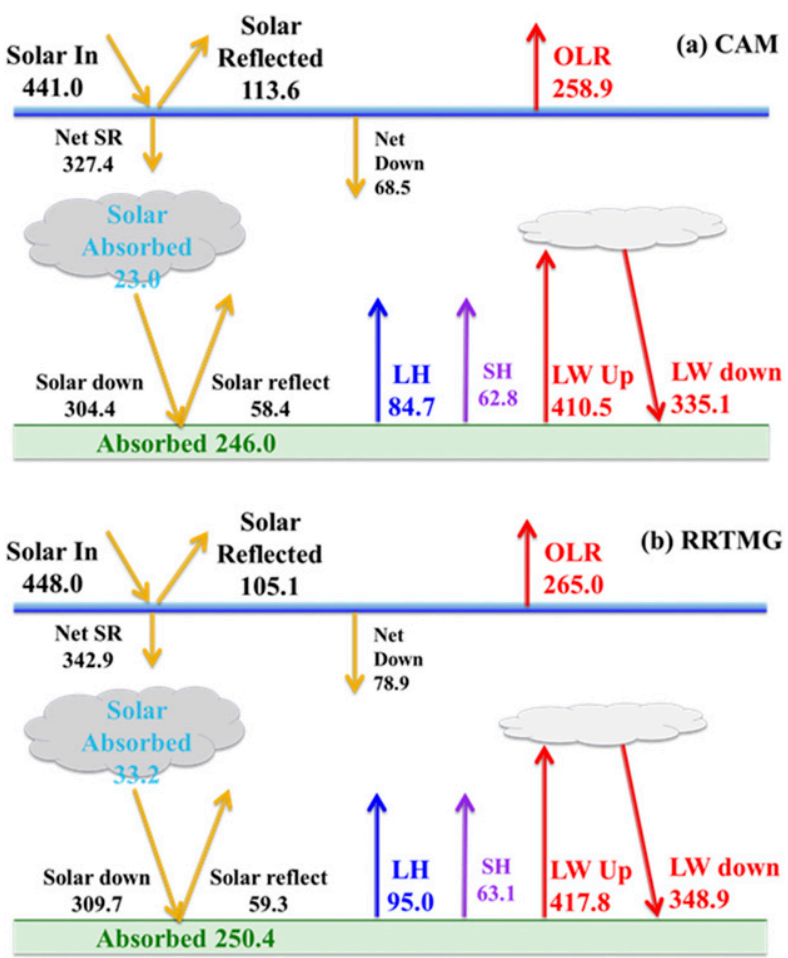

FIG. 7. Summer mean energy budget quantities $\left(\mathrm{W} \mathrm{m}^{-2}\right)$ at the top of the model $(10 \mathrm{hPa})$ and the surface for the period 1991-2000 over the Gulf Coast cluster for the (a) CAM and (b) RRTMG radiation schemes. Quantities shown are downward solar radiation (solar in), solar radiation reflected by atmosphere and clouds (solar reflect), solar radiation absorbed by the atmosphere (solar absorbed), solar radiation received at the surface (solar down), solar radiation reflected by the surface (solar reflect), latent heat (LH), sensible heat $(\mathrm{SH})$, emitted longwave radiation at the surface (LW up), longwave radiation emitted and reflected back to surface (LW down), and outgoing longwave radiation (OLR).

schemes. Their influence is most noticeable in the amplitudes of the 24-h harmonic.

\section{ANALYSIS OF ENERGY BUDGET QUANTITIES}

Figure 7 shows the summer mean energy budget quantities at the top of the model $(10 \mathrm{hPa})$ and at the surface, averaged over each station in the Gulf Coast. The values shown in Fig. 7 are the mean values for the simulations using CAM and the mean values for the simulations using RRTMG. This analysis of the energy budget quantities is in a regional domain where energy can be advected into or out of the domain. Consequently, the energy budget at the top of the model and at the surface do not balance. Figure 7 shows that RTTMG simulations receive $7 \mathrm{Wm}^{-2}$ more incoming solar radiation at the top of the model than simulations with the CAM scheme. Additionally, RRTMG simulations reflect $8.5 \mathrm{~W} \mathrm{~m}^{-2}$ less solar radiation. Consequently,
$15.5 \mathrm{~W} \mathrm{~m}^{-2}$ more solar radiation is absorbed by the surface and the atmosphere in the RRTMG simulations than in the CAM simulations.

Analysis of the solar radiation absorbed by the atmosphere (net solar at the top of the model minus solar radiation received at the surface) shows that $10.2 \mathrm{~W} \mathrm{~m}^{-2}$ of this extra $15.5 \mathrm{~W} \mathrm{~m}^{-2}$ is absorbed by the atmosphere and $5.3 \mathrm{~W} \mathrm{~m}^{-2}$ is received at the surface, of which $4.4 \mathrm{~W} \mathrm{~m}^{-2}$ is absorbed by the surface with the remaining $0.9 \mathrm{~W} \mathrm{~m}^{-2}$ reflected by the surface. So, compared to CAM simulations, the atmosphere in the RRTMG simulations absorbs $10.2 \mathrm{~W} \mathrm{~m}^{-2}$ more solar radiation and the surface absorbs $4.4 \mathrm{~W} \mathrm{~m}^{-2}$ more solar radiation. This suggests that both the atmosphere and the surface are warmer in the RRTMG simulations compared to the CAM simulations. The warmer surface is evident in Fig. 7, which shows that RRTMG simulations emit $7.3 \mathrm{~W} \mathrm{~m}^{-2}$ more longwave radiation than CAM simulations. This warmer surface leads to more evaporation at the surface in RRTMG simulations than CAM simulations; this is supported by the analysis in Fig. 7, which shows RRTMG simulations have $10.3 \mathrm{~W} \mathrm{~m}^{-2}$ more latent heat at the surface than CAM simulations.

Greater evaporation at the surface in the RRTMG simulations leads to more cloud cover and thus more surface upwelling longwave radiation reflected back to the surface. This is indeed the case, as RRTMG simulations receive $13.8 \mathrm{~W} \mathrm{~m}^{-2}$ more downward longwave radiation than CAM simulations. The additional cloud cover in the RRTMG simulations leads to more occurrences of precipitation in the RRTMG simulations than CAM. This increase in precipitation manifests itself in the amplitude of the diurnal cycle of precipitation with RRTMG simulations having a larger amplitude than CAM. This is perhaps unsurprising as the increased precipitation is due to the greater cloud cover in RRTMG simulations, which itself is a result of the additional solar radiation received at the top of the model-a quantity that also exhibits a diurnal cycle. Therefore, differences in the amplitude of the diurnal cycles simulated by CAM and RRTMG are likely due to the increases in solar radiation received from the top of the model, which enhances evaporation at the surface leading to increases in precipitation.

\section{e. Influence of physics combinations}

This section examines the influence of combinations of parameterization schemes on the simulated diurnal cycle. As Fig. 4 shows, while the phase of the diurnal cycle is largely unaffected by parameterizations other than cumulus schemes, the amplitude of the simulated 


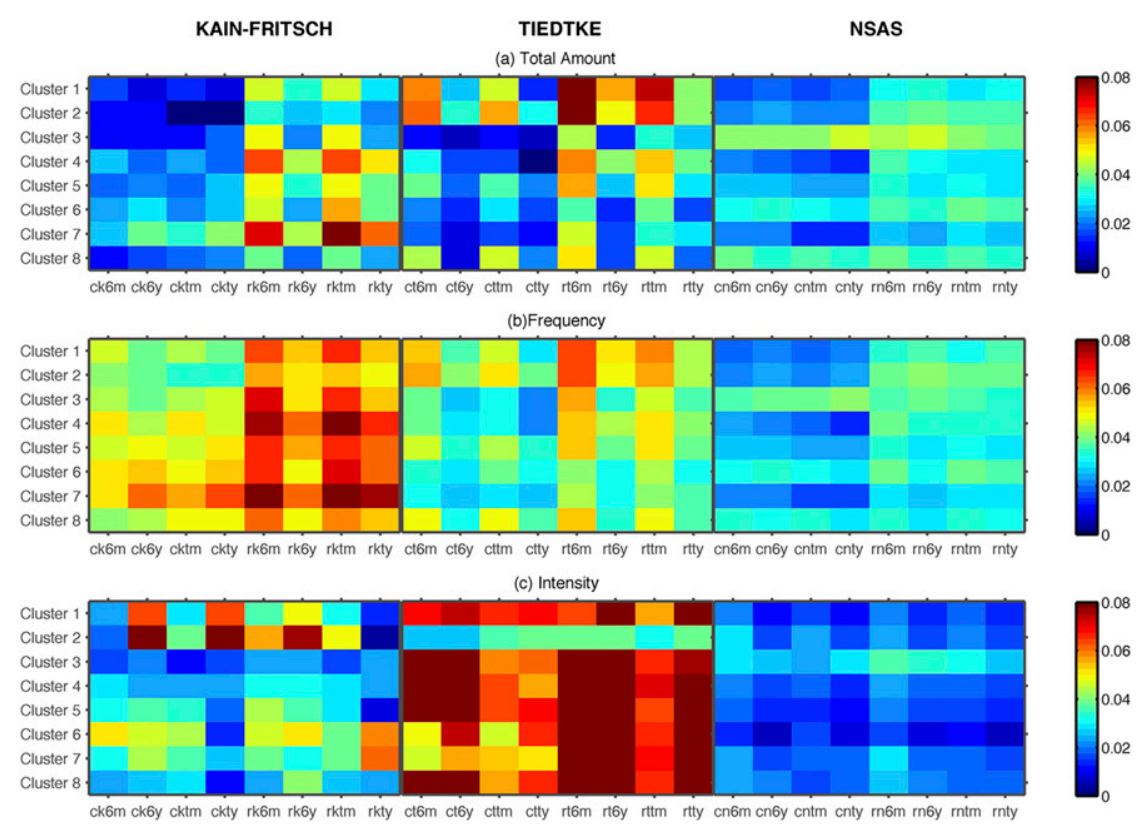

FIG. 8. Normalized amplitude (for details, see text) of the diurnal cycle of total (a) precipitation amount, (b) occurrences, and (c) intensity for each simulation and each cluster. The sections of each panel represent the simulations using the (left) Kain-Fritsch scheme (simulations 1-8 in Table 1), (center) Tiedtke scheme (simulations 9-16 in Table 1), and (right) NSAS scheme (simulations 17-24 in Table 1).

cycle is influenced by other schemes. Therefore, we focus on the effect of the combinations on the amplitude of the diurnal cycle. Figure 8 shows the normalized amplitude of each simulation ( $x$ axis) for each cluster ( $y$ axis). The amplitude of each simulation is normalized by dividing it by the sum of the amplitudes of all simulations in a cluster. Normalization according to each cluster removes the strong influence of geographical regions. If all simulations are insensitive to the combination of parameterization schemes, then the normalized amplitudes would have a value of 1/24 ( $\sim 0.04$; green boxes in Fig. 8); combinations of physics schemes that influence the simulated amplitude have values that are either greater than or less than 0.04 (red or blue, respectively, in Fig. 8).

Figure 8 shows the normalized amplitudes for the diurnal cycle of total precipitation amount (Fig. 8a), occurrences (Fig. 8b), and intensity (Fig. 8c), respectively. Focusing on precipitation amount, there is an obvious grouping across the plot with every second group of four simulations differing from the previous group of four simulations (CAM simulations are every first group of four while RRTMG are every second group). This demonstrates the dependence of the cycle's amplitude on the radiation scheme. The right side of both the Kain-Fritsch and Tiedtke groups show two clear vertical (orange/red) stripes, which correspond to combinations of the RRTMG radiation scheme and the MYJ PBL scheme. The NSAS scheme has some evidence of this effect but the difference between the RRTMG-MYJ and the RRTMG-YSU combinations is not substantial. This indicates that the diurnal cycle simulated by WRF is more sensitive to the chosen PBL scheme only when combined with the following combinations: RRTMG and Kain-Fritsch, RRTMG and Tiedtke, and CAM and Tiedtke. In contrast, the PBL schemes exert negligible influence on the amplitude of the cycle when combined with the NSAS cumulus scheme and the RRTMG radiation scheme.

This pattern of sensitivity just described is also evident in Fig. 8b, which shows the normalized amplitudes of precipitation occurrences. This is not surprising since the diurnal cycle of total precipitation amount is largely driven by occurrences.

The amplitude of the intensity (Fig. 8c) is strongly dominated by the influence of cumulus schemes and shows no clear evidence of an influence by physics combinations. This is likely due to the weak diurnal cycle present in the hourly intensity values. This is most evident in the Kain-Fritsch simulations, where differences in the normalized amplitudes appear almost random. 


\section{Summary}

Analysis of the 2141 rain gauges shows that the diurnal cycle of total summer amount has an afternoonevening peak in the east and west of the United States with the central United States having a peak that changes from late night to early morning. The observed amplitude is highest in the U.S. Southeast, the Gulf Coast, and the eastern Colorado-Kansas region (cluster 8). Spatial variations in the phase and amplitude of the observed diurnal cycle of rainfall occurrences are similar to the diurnal cycle of total amount. This contrasts with the observed diurnal cycle of intensity per occurrence whose phase shows no discernible variations spatially and occurs late in the evening at almost all locations. The amplitude of the diurnal cycle of intensity is small west of the Rockies relative to the amplitudes observed east of the Rockies. These results are consistent with previous observational studies of the contiguous United States (Dai et al. 1999a; Carbone and Tuttle 2008; Chen et al. 2009; Qiao and Liang 2015).

Spatial variations in the characteristics of the precipitation diurnal cycle were further explored using cluster analysis. Here 2141 stations were grouped according to similarities in key aspects of their cycle. Eight clusters with unique characteristics were identified across the United States. Characteristics of the mean diurnal cycle in each of these clusters were then analyzed and compared with the mean diurnal cycle in each cluster from the individual simulations.

Comparisons between observations and simulations show that the WRF multiphysics ensemble can simulate the phase and amplitude of the diurnal cycle of total precipitation amount in regions where the observed diurnal cycle of precipitation synchronizes with the diurnal cycle of surface temperature (e.g., U.S. East Coast). However, the model struggles to simulate the diurnal cycle of precipitation in regions where the phase of the observed diurnal cycle of precipitation does not coincide with the time of maximum surface temperature (e.g., the central United States). Analysis of the frequency and intensity showed that the simulated diurnal cycles have substantial biases in all clusters, namely, the overestimation of occurrences and the underestimation of intensities.

Analysis of the multiphysics ensemble showed that the cumulus schemes affected amplitude and phase of the simulated cycle, which is consistent with previous studies (Liang et al. 2004; Pei et al. 2014; Qiao and Liang 2015). In general, diurnal cycles simulated using the NSAS cumulus scheme have lower amplitudes than those simulated with either Kain-Fritsch or Tiedtke. In most clusters, simulations with the Kain-Fritsch cumulus scheme had a phase between 1400 and 1600 LT, while simulations using Tiedtke had a phase between 1200 and 1400 LT. This contrasts with simulations using the NSAS cumulus schemes, which had a more realistic phase that changes depending on the region. This result broadly agrees with other studies (e.g., Liang et al. 2004; Qiao and Liang 2015). Qiao and Liang (2015) systematically evaluated the performance of 12 cumulus parameterizations for summer floods in the central United States. They show that simulating the nocturnal rainfall in the central United States is sensitive to closure assumptions and trigger functions; specifically, they show that closure assumptions regulate the diurnal phase and nocturnal rainfall maxima, while the trigger function can inhibit daytime convection. Overall, the simulated diurnal cycle is sensitive to the choice of cumulus scheme, particularly in regions where the diurnal cycle is atypical (e.g., in the central United States where the diurnal cycle peaks in the late night and early morning).

Radiation schemes also influenced the model's ability to simulate the amplitude of the diurnal cycle; however, their influence on the phase was much less apparent. Planetary boundary layer schemes and microphysics schemes showed no clear impact on the model's ability to simulate the diurnal cycle. However, a study of the combinations of physics parameterizations showed that WRF simulations with the RRTMG radiation scheme used with either the Kain-Fritsch or Tiedtke cumulus scheme are sensitive to the chosen PBL schemes, whereas combinations of NSAS and RRTMG do not show this sensitivity. These results are consistent with the fact that Kain-Fritsch and Tiedtke, which have similar closure assumptions, are more strongly coupled to surface forcing than the NSAS scheme; the latter of which has a closure assumption that ties convection to the tendency of large-scale instability. Consequently, simulations with NSAS are less responsive to boundary layer processes than the simulations with Kain-Fritsch and Tiedtke. As these findings relate exclusively to the contiguous United States it is possible that similar studies conducted for different parts of the world may yield dissimilar results, particularly given the role of regionally specific processes in influencing the cycle's unique characteristics.

\section{Conclusions}

This study highlights the benefits of regionalization through clustering of individual stations as a diagnostic approach for interrogating model performance. Regionalization allows better understanding of the cycle's characteristics and the role of regional-scale forcings. Hence, in contrast to analysis based on gridbox 
proximity, regionalization provides a more physically consistent basis for model assessment and lends itself to more easily uncovering deficiencies in how the model captures particular drivers. It is recommended that similar studies should consider model performance based on physically meaningful regions.

For this purpose the contiguous United States is a particularly attractive location for evaluating model performance. It presents particularly unique conditions for model assessment as a result of the diversity of diurnal cycles and associated physical drivers throughout the region. This is further enhanced by the availability of a highquality data-rich observational network. In the case of the contiguous United States, any future model analyses in relation to the diurnal cycle should consider adopting the regions identified in the present study.

Additionally, the study highlights that all parameterizations fail to capture most of the major characteristics of the diurnal cycle accurately, particularly when it departs from typical behavior. Furthermore, differences between schemes when considered in the context of the overall model error appear less distinct. However, the study does find that differences between schemes exist, and in so doing highlights those parameterizations that better represent the most important physical processes and which offer the best line of investigation for further improving model performance.

This adds to our knowledge of the current limitations and capabilities of dynamical models and highlights potential pathways for further enhancing their representation of precipitation dynamics across different spatiotemporal scales. Such knowledge is fundamental for improving the skill of near-term weather forecasts, and given their importance as a downscaling tool-in which boundary conditions are provided by global climate models-the accuracy of projected changes in regional precipitation regimes in response to longer-term climate change (Harding et al. 2013; Wang and Kotamarthi 2015). In this context the study also informs how we should interpret the likely accuracy of model simulations in relation to the diurnal cycle, highlighting that considerable scope for improvement exists, and as such this is an important area for further research.

Acknowledgments. NCAR is sponsored by the National Science Foundation. This work was partially supported by NSF EASM Grant AGS-1048829, DOE Grant RFP2010UDW001-4082, and the Research Partnership to Secure Energy for America. The authors acknowledge high-performance computing support from Yellowstone (http://n2t.net/ark:/85065/d7wd3xhc) provided by NCAR's Computational and Information Systems Laboratory, sponsored by the National Science
Foundation. ERA-Interim data used in this study have been obtained from the ECMWF data server (http:// apps.ecmwf.int/datasets/). We thank Kerry H. Cook, The University of Texas at Austin; Pedro Montávez, University of Murcia, Spain; and two anonymous reviewers for helpful comments that improved the final version of this manuscript. The authors thank the National Climatic Data Center for making the DSI-3240 dataset freely available online (ftp://ftp.ncdc.noaa.gov/ pub/data/hourly_precip-3240/).

\section{APPENDIX}

\section{Effect of Bucket Size on Results}

As mentioned in the main manuscript, stations that recorded precipitation at the lower precision of $2.54 \mathrm{~mm}$ were included in the main manuscript while those with the higher precision of $0.254 \mathrm{~mm}$ were excluded-primarily as there were too few of the lower-precision stations to provide sufficient coverage across the contiguous United States. However, we used the higher-precision data here to examine the effect of the bucket size on the comparison of modeled with observed data. These higher-resolution stations are distributed more or less uniformly across the contiguous United States, which means that their overall average is representative of a continental-type climate and the mean is not dominated by any one cluster type. The higher precision of the recorded data enabled us to examine the diurnal cycle of precipitation assuming six different bucket sizes by binning the data as follows: $0.25,0.5,0.76,1.27,1.77$, and $2.54 \mathrm{~mm}$. Figure A1 shows the phase and amplitude of the total rainfall amount, number of occurrences, and intensity per occurrence as a function of bucket size for the observations and the 24 WRF simulations.

Figures A1a,b show that the phase and amplitude of the diurnal cycle of total rainfall amount in the observations and in all simulations was independent of the bucket size. Similar findings are shown for the phase of the observed diurnal cycle of occurrences (Fig. A1c), and the phase of the cycles simulated using either the Kain-Fritsch or Tiedtke cumulus scheme, respectively. Only diurnal cycles simulated with the NSAS cumulus scheme had phases that were affected by the bucket size. In this case, the phase shifts one or two hours later in the afternoon as the bucket sizes increase. This is due to a double peak in the NSAS simulated cycles where the dominant peak, which occurs earlier, decreases relative to increases in bucket size. Thus, the influence of the secondary peak increases, shifting the phase to later in 
(a) Total Amount

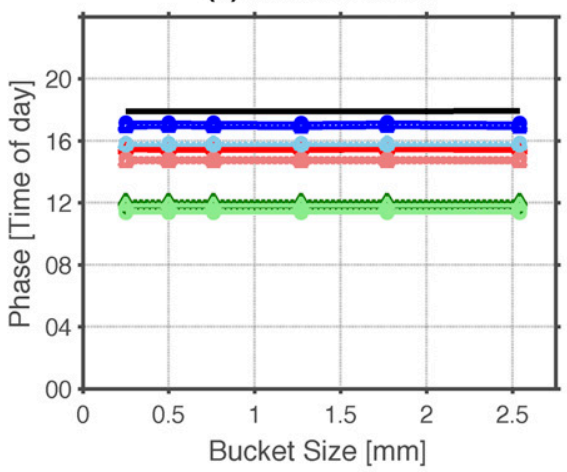

(c) Frequency

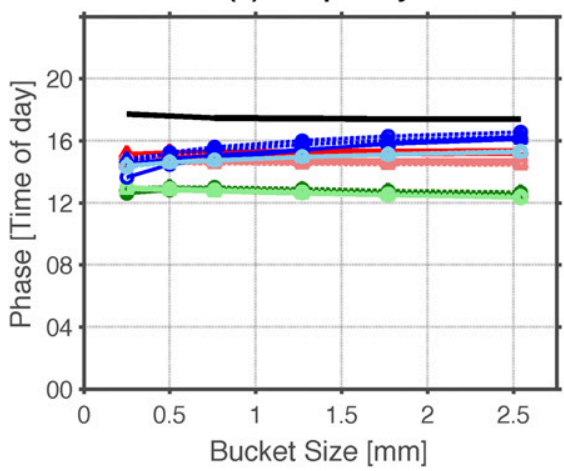

(e) Intensity

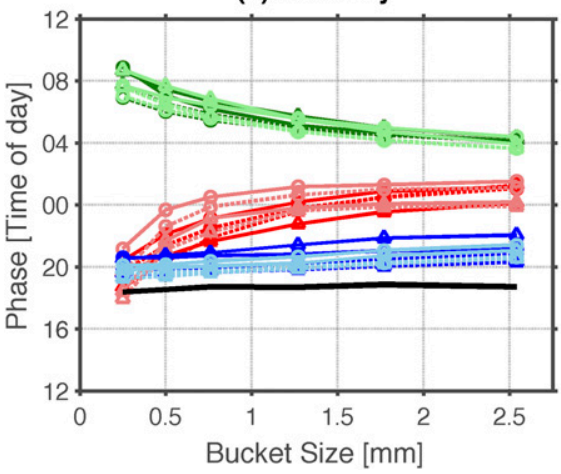

(b) Total Amount

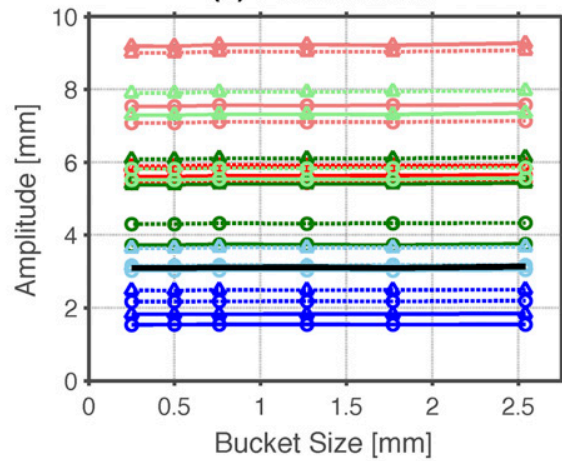

(d) Frequency

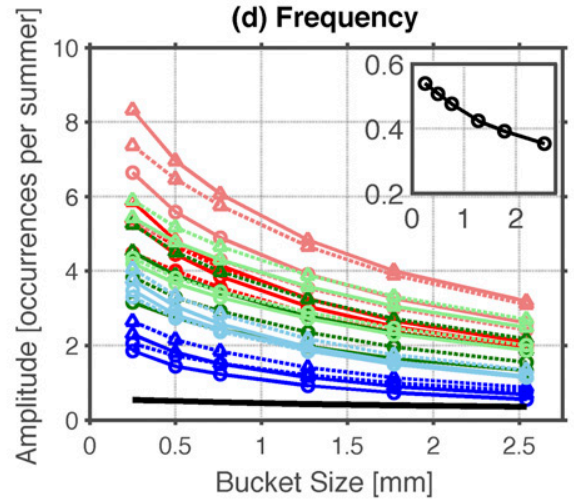

(f) Intensity

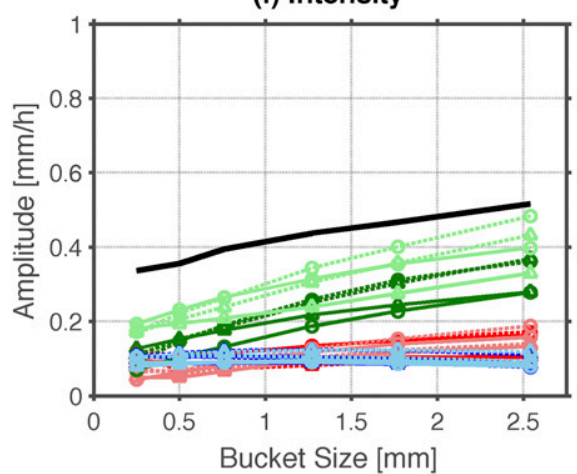

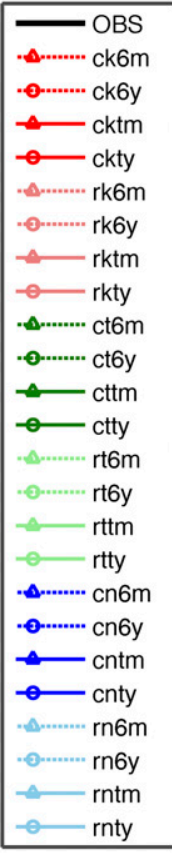

FIG. A1. (a) Phase and (b) amplitude of the observed and simulated diurnal cycles of total precipitation amount in summer averaged over 220 stations throughout the United States. (c),(d) As in (a),(b), but for the diurnal cycle of precipitation occurrences. The inset in (d) shows the amplitude of the observed diurnal cycle with the $y$ axis rescaled. (e),(f) As in (a),(b), but for the diurnal cycle of intensity per occurrence. the afternoon as the bucket size increases. Figure A1d shows that the amplitude of the observed and simulated diurnal cycle of occurrences is affected by the bucket size; the amplitude decreases as the bucket size increases as would be expected since an occurrence is defined by the bucket size used. However, it should be noted that the amplitudes of the simulated diurnal cycles decrease faster than the amplitude of the observed cycle; this is due to the model's tendency to overpredict the occurrences of light precipitation.
The phase and amplitude of the observed and simulated diurnal cycles of intensity are shown in Figs. A1e,f. The phase of the observed diurnal cycle is unaffected by the bucket size; however, it is noted that the amplitude increases as the bucket size increases. The simulated amplitudes follow the same pattern as the observations. However, the phase of the diurnal cycles simulated using Kain-Fritsch and Tiedtke behave differently than the observations, showing distinct changes as the bucket size increases. As described 
earlier, the simulated diurnal cycles of intensity are considerably weaker than the observed and hence exhibit greater variability.

In summary, changing the bucket size does not affect the amplitude and phase of the diurnal cycle of total rainfall amount. This means that comparisons between the simulated and observed diurnal cycle of total precipitation amount are unaffected by bucket size. This contrasts with the amplitudes of the diurnal cycles of occurrence and intensity, which are dependent on bucket size. Hence, in these cases caution needs to be exercised. Although the absolute values of the amplitudes change as the bucket size increases, the general pattern is independent of the bucket size (i.e., the amplitude of the simulated diurnal cycle of occurrence is always greater than the amplitude of the observed diurnal cycle); conversely the amplitude of the simulated diurnal cycle of intensity is always less than the amplitude of the observed diurnal cycle. Based on the outcome of this subsidiary study, we proceed with the main investigation aware of the effects of bucket size on the analysis.

\section{REFERENCES}

Argueso, D., A. Di Luca, and J. P. Evans, 2016: Precipitation over urban areas in the western Maritime Continent using a convection-permitting model. Climate Dyn., 47, 1143-1159, doi:10.1007/s00382-015-2893-6.

Ban, N., J. Schmidli, and C. Schär, 2014: Evaluation of the convection-resolving regional climate modeling approach in decade-long simulations. J. Geophys. Res. Atmos., 119, 7889-7907, doi:10.1002/2014JD021478.

Birch, C. E., M. J. Roberts, L. Garcia-Carreras, D. Ackerley, M. J. Reeder, A. P. Lock, and R. Schiemann, 2015: Sea-breeze dynamics and convection initiation: The influence of convective parameterization in weather and climate model biases. J. Climate, 28, 8093-8108, doi:10.1175/JCLI-D-14-00850.1.

Bonner, W. D., 1968: Climatology of the low level jet. Mon. Wea. Rev., 96, 833-849, doi:10.1175/1520-0493(1968)096<0833: COTLLJ $>2.0 . \mathrm{CO} ; 2$.

Brockhaus, P., D. Lüthi, and C. Schär, 2008: Aspects of the diurnal cycle in a regional climate model. Meteor. Z., 17, 433-443, doi:10.1127/0941-2948/2008/0316.

Bruyère, C. L., and Coauthors, 2017: Impact of climate change on Gulf of Mexico hurricanes. NCAR Tech. Note NCAR/ TN-535+STR, 165 pp., doi:10.5065/D6RN36J3.

Carbone, R. E., and J. D. Tuttle, 2008: Rainfall occurrence in the U.S. warm season: The diurnal cycle. J. Climate, 21, 4132-4146, doi:10.1175/2008JCLI2275.1.

$\longrightarrow,-$ D. A. Ahijevych, and S. B. Trier, 2002: Inferences of predictability associated with warm season precipitation episodes. J. Atmos. Sci., 59, 2033-2056, doi:10.1175/ 1520-0469(2002)059<2033:IOPAWW>2.0.CO;2.

Chen, H., T. Zhou, R. Yu, and J. Li, 2009: Summer rain fall duration and its diurnal cycle over the US Great Plains. Int. J. Climatol., 29, 1515-1519, doi:10.1002/joc.1806.
Collier, J. C., and K. P. Bowman, 2004: Diurnal cycle of tropical precipitation in a general circulation model. J. Geophys. Res., 109, D17105, doi:10.1029/2004JD004818.

Collins, W. D., and Coauthors, 2004: Description of the NCAR Community Atmosphere Model (CAM 3.0). NCAR Tech. Note TN-464+STR, 226 pp.

Cornes, R. C., and P. D. Jones, 2013: How well does the ERAInterim reanalysis replicate trends in extremes of surface temperature across Europe? J. Geophys. Res. Atmos., 118, $10262-10276$, doi:10.1002/jgrd.50799.

Dai, A., 2001: Global precipitation and thunderstorm frequencies. Part II: Diurnal variations. J. Climate, 14, 1112-1128, doi:10.1175/1520-0442(2001)014<1112: GPATFP $>2.0 . \mathrm{CO} ; 2$.

— , and K. E. Trenberth, 2004: The diurnal cycle and its depiction in the Community Climate System Model. J. Climate, 17, 930-951, doi:10.1175/1520-0442(2004)017<0930: TDCAID $>2.0 . \mathrm{CO} ; 2$.

— simulated diurnal cycles of precipitation over the contiguous United States. J. Geophys. Res., 104, 6377-6402, doi:10.1029/ 98JD02720.

— , K. E. Trenberth, and T. R. Karl, 1999b: Effects of clouds, soil moisture, precipitation, and water vapor on diurnal temperature range. J. Climate, 12, 2451-2473, doi:10.1175/ 1520-0442(1999)012<2451:EOCSMP $>2.0$.CO;2.

— X. Lin, and K.-L. Hsu, 2007: The frequency, intensity, and diurnal cycle of precipitation in surface and satellite observations over low- and mid-latitudes. Climate Dyn., 29, 727744, doi:10.1007/s00382-007-0260-y.

Dee, D. P., and Coauthors, 2011: The ERA-Interim reanalysis: Configuration and performance of the data assimilation system. Quart. J. Roy. Meteor. Soc., 137, 553-597, doi:10.1002/qj.828.

Diro, G. T., S. A. Raischer, F. Giorgi, and A. M. Tompkins, 2012: Sensitivity of seasonal climate and diurnal precipitation over Central America to land and sea surface schemes in RegCM4. Climate Res., 52, 31-48, doi:10.3354/cr01049.

Ek, M., and L. Mahrt, 1991: OSU 1-D PBL model: User's guide, version 1.04. Oregon State University Department of Atmospheric Sciences Rep., 126 pp.

Evans, J., and S. Westra, 2012: Investigating the mechanisms of diurnal rainfall variability using a regional climate model. J. Climate, 25, 7232-7247, doi:10.1175/JCLI-D-11-00616.1.

Fu, G., S. P. Charles, B. Timbal, B. Jovanovic, and F. Ouyang, 2015: Comparison of NCEP-NCAR and ERA-Interim over Australia. Int. J. Climatol., 36, 2345-2367, doi:10.1002/ joc. 4499 .

Gianotti, R. L., D. Zhang, and E. A. B. Eltahir, 2012: Assessment of the regional climate model version 3 over the Maritime Continent using different cumulus parameterization and land surface schemes. J. Climate, 25, 638-656, doi:10.1175/ JCLI-D-11-00025.1.

Hammer, G. R., and P. M. Steurer, 1997: Data set documentation for hourly precipitation data. NOAA/NCDC Tech. Doc. TD3240, 18 pp.

Han, J., and H.-L. Pan, 2011: Revision of convection and vertical diffusion schemes in the NCEP Global Forecasting System. Wea. Forecasting, 26, 520-533, doi:10.1175/ WAF-D-10-05038.1.

Harding, K. J., P. K. Synder, and S. Leiss, 2013: Use of dynamical downscaling to improve the simulation of central U.S. warm season precipitation in CMIP5 models. J. Geophys. Res. Atmos., 118, 522-536, doi:10.1002/2013JD019994. 
Hong, S.-Y., J. Dudhia, and S.-H. Chen, 2004: A revised approach to ice-microphysical processes for the bulk parameterizations of cloud and precipitation. Mon. Wea. Rev., 132, 103-120, doi:10.1175/1520-0493(2004)132<0103:ARATIM>2.0.CO;2.

_, Y. Noh, and J. Dudhia, 2006: A new vertical diffusion package with an explicit treatment of entrainment processes. Mon. Wea. Rev., 134, 2318-2341, doi:10.1175/MWR3199.1.

Jeong, J.-H., A. Walther, G. Nikulin, D. Chen, and C. Jones, 2011: Diurnal cycle of precipitation amount and frequency in Sweden: Observation versus model simulation. Tellus, 63A, 664-674, doi:10.1111/j.1600-0870.2011.00517.x.

Jin, E. K., I. J. Choi, S.-Y. Kim, and J.-Y. Han, 2016: Impact of model resolution on the simulation of diurnal variations of precipitation over East Asia. J. Geophys. Res. Atmos., 121, 1652-1670, doi:10.1002/2015JD023948.

Jin, J., N. L. Miller, and N. Schlegel, 2010: Sensitivity study of four land surface schemes in the WRF Model. Adv. Meteor., 2010, 167436, doi:10.1155/2010/167436.

Kain, J. S., 2004: The Kain-Fritsch convective parameterization: An update. J. Appl. Meteor., 43, 170-181, doi:10.1175/ 1520-0450(2004)043<0170:TKCPAU > 2.0.CO;2.

_, and J. M. Fritsch, 1990: A one-dimensional entraining/ detraining plume model and its application in convective parameterization. J. Atmos. Sci., 47, 2784-2802, doi:10.1175/ 1520-0469(1990)047<2784:AODEPM>2.0.CO;2.

Kikuchi, K., and B. Wang, 2008: Diurnal precipitation regimes in the global tropics. J. Climate, 21, 2680-2696, doi:10.1175/ 2007JCLI2051.1.

Klingaman, N. P., and S. J. Woolnough, 2014: The role of air-sea coupling in the simulation of the Madden-Julian oscillation in the Hadley Centre model. Quart. J. Roy. Meteor. Soc., 140, 2272-2286, doi:10.1002/qj.2295.

Lee, M.-I., S. D. Schubert, M. J. Suarez, J.-K. E. Schemm, H.-L. Pan, J. Han, and S.-H. Yoo, 2008: Role of convection triggers in the simulation of the diurnal cycle of precipitation over the United States Great Plains in a general circulation model. J. Geophys. Res., 113, D02111, doi:10.1029/2007JD008984.

Liang, X.-Z., L. Li, A. Dai, and K. E. Kunkel, 2004: Regional climate model simulation of summer precipitation diurnal cycle over the United States. Geophys. Res. Lett., 31, L24208, doi:10.1029/2004GL021054.

Masson, S., P. Terray, G. Madec, J. J. Luo, T. Yamagata, and K. Takahashi, 2012: Impact of intra-daily SST variability on ENSO characteristics in a coupled model. Climate Dyn., 39, 681-707, doi:10.1007/s00382-011-1247-2.

Mellor, G. L., and T. Yamada, 1982: Development of a turbulence closure model for geophysical fluid problems. Rev. Geophys., 20, 851-875, doi:10.1029/RG020i004p00851.

Mlawer, E. J., S. J. Taubman, P. D. Brown, M. J. Iacono, and S. A. Clough, 1997: Radiative transfer for inhomogeneous atmosphere: RRTM, a validated correlated-k model for the longwave. J. Geophys. Res., 102, 16 663-16 682, doi:10.1029/97JD00237.

Mooney, P. A., F. J. Mulligan, and R. Fealy, 2011: Comparison of ERA-40, ERA-Interim and NCEP/NCAR reanalysis data with observed surface air temperatures over Ireland. Int. J. Climatol., 31, 545-557, doi:10.1002/joc.2098.

,-- , and 2013: Evaluation of the sensitivity of the Weather Research and Forecasting Model to parameterization schemes for regional climates of Europe over the period 1990-1995. J. Climate, 26, 1002-1017, doi:10.1175/ JCLI-D-11-00676.1.

$\longrightarrow,-$, and C. Broderick, 2016: Diurnal cycle of precipitation over the British Isles in a $0.44^{\circ}$ WRF multiphysics regional climate ensemble over the period 1990-1995. Climate Dyn., 47, 3281-3300, doi:10.1007/s00382-016-3026-6.

Oh, J. H., B. M. Kim, K. Y. Kim, H. J. Song, and G. H. Lim, 2013: The impact of the diurnal cycle on the MJO over the Maritime Continent: A modeling study assimilating TRMM rain rate into global analysis. Climate Dyn., 40, 893-911, doi:10.1007/ s00382-012-1419-8.

Oki, T., and K. Musiake, 1994: Seasonal change of the diurnal cycle of precipitation over Japan and Malaysia. J. Appl. Meteor., 33, 1899-1922, doi:10.1175/1520-0450(1994)033<1445: $\mathrm{SCOTDC}>2.0 . \mathrm{CO} ; 2$.

PaiMazumder, D., and J. M. Done, 2016: Potential predictability sources of the 2012 US drought in observations and a regional model ensemble. J. Geophys. Res. Atmos., 121, 12 581-12 592, doi:10.1002/2016JD025322.

Pei, L., N. Moore, S. Zhong, L. Luo, D. W. Hyndman, W. E. Heilman, and Z. Gao, 2014: WRF Model sensitivity to land surface model and cumulus parameterization under shortterm climate extremes over the southern Great Plains of the United States. J. Climate, 27, 7703-7724, doi:10.1175/ JCLI-D-14-00015.1.

Perdinan, and J. A. Winkler, 2015: Selection of climate information for regional climate change assessments using regionalization techniques: An example for the Upper Great Lakes Region, USA. Int. J. Climatol., 35, 1027-1040, doi:10.1002/ joc.4036.

Prat, O. P., and B. R. Nelson, 2014: Characteristics of annual, seasonal, and diurnal precipitation in the southeastern United States derived from long-term remotely sensed data. Atmos. Res., 144, 4-20, doi:10.1016/j.atmosres.2013.07.022.

Qiao, F., and X.-Z. Liang, 2015: Effects of cumulus parameterizations on predictions of summer flood in the central United States. Climate Dyn., 45, 727-744, doi:10.1007/s00382-014-2301-7.

Rousseeuw, P. J., 1987: Silhouettes: A graphical aid to the interpretation and validation of cluster analysis. J. Comput. Appl. Math., 20, 53-65, doi:10.1016/0377-0427(87)90125-7.

Ruppert, J. H., 2016: Diurnal timescale feedbacks in the tropical cumulus regime. J. Adv. Model. Earth Syst., 8, 319-344, doi:10.1002/2016MS000713.

Sapiano, M. R. P., and P. A. Arkin, 2009: An intercomparison and validation of high-resolution satellite precipitation estimates with 3-hourly gauge data. J. Hydrometeor., 10, 149-166, doi:10.1175/2008JHM1052.1.

Skamarock, W. C., and Coauthors, 2008: A description of the Advanced Research WRF version 3. NCAR Tech. Note NCAR/TN-475+STR, 113 pp., doi:10.5065/D68S4MVH.

Svensson, C., and D. Jakob, 2002: Diurnal and seasonal characteristics of precipitation at an upland site in Scotland. Int. J. Climatol., 22, 587-598, doi:10.1002/joc.674.

Thompson, G., P. R. Field, R. M. Rasmussen, and W. D. Hall, 2008: Explicit forecasts of winter precipitation using an improved bulk microphysics scheme. Part II: Implementation of a new snow parameterization. Mon. Wea. Rev., 136, 50955115, doi:10.1175/2008MWR2387.1.

Tiedtke, M., 1989: A comprehensive mass flux scheme for cumulus parameterization in large-scale model. Mon. Wea. Rev., 117, 1779-1800, doi:10.1175/1520-0493(1989)117<1779: ACMFSF $>2.0 . \mathrm{CO} ; 2$.

Twardosz, R., 2007: Seasonal characteristics of diurnal precipitation variation in Kraków (south Poland). Int. J. Climatol., 27, 957-968, doi:10.1002/joc.1439.

Wallace, J., 1975: Diurnal variations in precipitation and thunderstorm frequency over the conterminous United States. Mon. 
Wea. Rev., 103, 406-419, doi:10.1175/1520-0493(1975)103<0406: DVIPAT $>2.0 . \mathrm{CO} ; 2$.

Walther, A., J.-H. Jeong, G. Nikulin, C. Jones, and C. Deliang, 2013: Evaluation of the warm season diurnal cycle of precipitation over Sweden simulated by the Rossby Centre regional climate model RCA3. Atmos. Res., 119, 131-139, doi:10.1016/j.atmosres.2011.10.012.

Wang, J., and V. R. Kotamarthi, 2015: High-resolution dynamically downscaled projections of precipitation in the mid and late 21st century over North America. Earth's Future, 3, 268-288, doi:10.1002/2015EF000304.

Wilks, D. S., 2011: Statistical Methods in the Atmospheric Sciences. Academic Press, 704 pp.
Winkler, J. A., 1987: Diurnal variations of summertime very heavy precipitation in the eastern and central United States. Phys. Geogr., 8, 210-224.

Yang, G., and J. Slingo, 2001: The diurnal cycle in the tropics. Mon. Wea. Rev., 129, 784-801, doi:10.1175/1520-0493(2001)129<0784: TDCITT $>2.0 . C O ; 2$.

Yaqub, A., P. Seibert, and H. Formayer, 2011: Diurnal precipitation cycle in Austria. Theor. Appl. Climatol., 103, 109118, doi:10.1007/s00704-010-0281-z.

Zhang, G., K. H. Cook, and E. K. Vizy, 2016: The diurnal cycle of warm season rainfall over West Africa. Part II: Convection-permitting simulations. J. Climate, 29, 84398454, doi:10.1175/JCLI-D-15-0875.1. 